\title{
How Chain Length and Branching Influence the Alkene Cracking Reactivity on H-ZSM-5
}

\author{
Pieter Cnudde, Kristof De Wispelaere, Louis Vanduyfhuys, Ruben Demuynck, ${ }^{\circ}$ \\ Jeroen Van der Mynsbrugge, ${ }^{\ddagger 0}$ Michel Waroquier, and Veronique Van Speybroeck*(i) \\ Center for Molecular Modeling, Ghent University, Technologiepark 903, B-9052, Zwijnaarde, Belgium
}

\author{
Supporting Information
}

\begin{abstract}
Catalytic alkene cracking on H-ZSM-5 involves a complex reaction network with many possible reaction routes and often elusive intermediates. Herein, advanced molecular dynamics simulations at $773 \mathrm{~K}$, a typical cracking temperature, are performed to clarify the nature of the intermediates and to elucidate dominant cracking pathways at operating conditions. A series of $\mathrm{C}_{4}-\mathrm{C}_{8}$ alkene intermediates are investigated to evaluate the influence of chain length and degree of branching on their stability. Our simulations reveal that linear, secondary carbenium ions are relatively unstable, although their lifetime increases with carbon number. Tertiary carbenium ions, on the other hand, are shown to be very stable, irrespective of the chain length. Highly branched carbenium ions, though, tend to rapidly

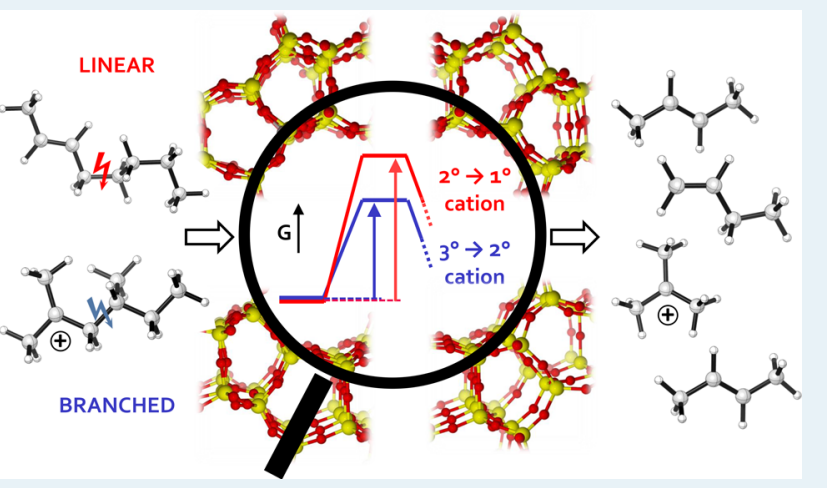
rearrange into more stable cationic species, either via cracking or isomerization reactions. Dominant cracking pathways were determined by combining these insights on carbenium ion stability with intrinsic free energy barriers for various octene $\beta$-scission reactions, determined via umbrella sampling simulations at operating temperature $(773 \mathrm{~K})$. Cracking modes $\mathrm{A}\left(3^{\circ} \rightarrow 3^{\circ}\right)$ and $\mathrm{B}_{2}\left(3^{\circ} \rightarrow 2^{\circ}\right)$ are expected to be dominant at operating conditions, whereas modes $\mathrm{B}_{1}\left(2^{\circ} \rightarrow 3^{\circ}\right), \mathrm{C}\left(2^{\circ} \rightarrow 2^{\circ}\right), \mathrm{D}_{2}\left(2^{\circ} \rightarrow 1^{\circ}\right)$, and $\mathrm{E}_{2}\left(3^{\circ} \rightarrow 1^{\circ}\right)$ are expected to be less important. All $\beta$-scission modes in which a transition state with primary carbocation character is involved have high intrinsic free energy barriers. Reactions starting from secondary carbenium ions will contribute less as these intermediates are short living at the high cracking temperature. Our results show the importance of simulations at operating conditions to properly evaluate the carbenium ion stability for $\beta$-scission reactions and to assess the mobility of all species in the pores of the zeolite.
\end{abstract}

KEYWORDS: alkene cracking, chain length, H-ZSM-5, carbenium ion, $\beta$-scission, molecular dynamics, umbrella sampling, free energy

\section{INTRODUCTION}

Zeolite-catalyzed alkene cracking is omnipresent in many petrochemical processes for the production of fuels and light olefins. $^{1-4}$ Recently, the increase in shale gas recovery and interest in renewable feedstocks have reinforced the search for new technologies to fulfill the rising propene demand. As a result, propene on-purpose processes have become an economically viable alternative for the conventional steam cracking technology. ${ }^{5-9}$ In this context, catalytic alkene cracking has gained importance (e.g., to increase light olefin yields in product streams with a high content of less valuable $\mathrm{C}_{4}-\mathrm{C}_{8}$ alkenes). ${ }^{9,10}$ Despite the wide application of alkene cracking, the nature of the reactive intermediates remains unclear., ${ }^{3,11,12}$ Experimentally tracking individual reactions at the high operating temperatures $(773-833 \mathrm{~K})$ is a difficult task due to the occurrence of elusive intermediates and many side reactions. $^{13-18}$ Nowadays, molecular modeling techniques have matured to a level where zeolite catalyzed reactions can be modeled at true operating conditions, using advanced sampling techniques which allow to reconstruct the free energy surface. $^{18}$
Herein, we unravel the stability and reactivity of typical alkene cracking intermediates at operating conditions with firstprinciple-based molecular dynamics methods. We show that static methods relying on a limited number of points on the potential energy surface inadequately account for the conformational mobility and temperature effects, hence giving a limited view on the zeolite catalyzed transformations under study. For alkane cracking, some molecular dynamics-based modeling studies clearly showed the importance of accounting for true operating conditions to unravel the nature of reactive intermediates and predict accurate product selectivities. ${ }^{16}$ Bučko et al. studied propane cracking in $\mathrm{H}-\mathrm{CHA}$ and found that alkanes move rather freely in the zeolite pores at elevated temperature. ${ }^{19}$ Later, this was also confirmed by Jiang et al., who studied the effect of temperature on the adsorption of short alkanes in SSZ-13. ${ }^{20}$ Bell and co-workers showed for $n$-pentane and $n$-hexane cracking in H-ZSM-5 that more realistic product

Received: May 7, 2018

Revised: July 9, 2018

Published: September 5, 2018 
selectivities were obtained by means of innovative quasiclassical trajectory simulations. ${ }^{21,22}$

Upon alkene adsorption at the Brønsted acid site (BAS) of the catalyst, four different intermediates can be identified, as depicted in Scheme 1. A physisorbed van der Waals complex

\section{Scheme 1. Four Possible Adsorption States of a 2-Alkene ${ }^{a}$}<smiles>[R]C/C=C\C</smiles>

1<smiles>C1=CC=C1</smiles><smiles>[R]CC1=C(C)C(O[Si](C)(C)O[Si]C)C1[Si](C)C</smiles>

2 chemisorption<smiles>[R]CC[CH-]C(C)O[Si](C)(C)O[Si]C</smiles>

3

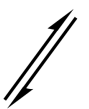<smiles>[R]CCC(C)O[Si](C)(C)O[Si]C</smiles>

4
${ }^{a}$ 1: van der Waals complex, 2: $\pi$-complex, 3 : carbenium ion, 4: alkoxide.

(1) is characterized by only dispersion interactions between the alkene and the zeolite walls. If the alkene double bond interacts with the acid proton, a physisorbed $\pi$-complex (2) is formed. Two chemisorbed intermediates can occur upon protonation of the double bond, either a carbenium ion (3) or a framework bound alkoxide (4). Especially the nature of the chemisorbed intermediates is strongly debated. ${ }^{16,23-26}$ Despite the availability of many studies on the stability of carbenium ions and their impact on $\beta$-scission reactions, only a limited number of modeling studies are available on carbenium ion chemistry at operating conditions. ${ }^{27,28}$

The high reactivity of alkenes hampers the experimental characterization of the often short-lived intermediates. ${ }^{16,18}$ Aside from a series of $\mathrm{NMR}^{29-35}$ and FT-IR ${ }^{26,36-41}$ studies, the nature of chemisorbed alkenes has mainly been studied theoretically. Early computational studies were carried out on small zeolite cluster models, consisting of only a few $\mathrm{T}$ atoms. $^{42-49}$ These spectroscopy experiments and cluster calculations both identified alkoxides as stable intermediates. Recently, Sarazen and Iglesia addressed the stability of bound species during alkene reactions on solid acids by a combined in situ infrared and density functional theory (DFT) study. ${ }^{50,51}$ Carbenium ions, on the other hand, were suggested to act as transition-state species rather than cracking intermediates. ${ }^{25,52,53}$ However, spectroscopy studies are typically carried out at relatively low temperatures. Since entropy effects disfavor the formation of framework-bound alkoxides, ${ }^{27}$ different conclusions may arise at cracking temperatures. Furthermore, small cluster calculations lack a proper description of the zeolite confinement which may complicate alkoxide and facilitate carbenium ion formation. $16,17,54-57$

The existence of stable carbenium ions was proposed in a number of computational studies on extended cluster models or periodically repeated unit cells. ${ }^{24,27,28,58-61}$ Fang et al. concluded that the accommodation of the hydrocarbons inside the zeolite framework is a crucial factor in determining carbenium ion stability. ${ }^{61}$ The accommodation of carbenium ions is in addition influenced by the length of the adsorbed olefin. ${ }^{62,63}$ Upon comparison with small cluster models, it was indicated that steric constraints destabilize bulky alkoxides relative to carbenium ions. Boronat et al. also stated that alkoxide stability is sensitive to the framework type as well as the position and local environment of the acid site. ${ }^{24,55}$ Next to the zeolite topology, the stability of the intermediates and the cracking activity are also influenced by the acid strength of the zeolite. $^{64-67} \mathrm{Chu}$ et al. demonstrated that the reactivity of dimerization and cracking reactions can be significantly enhanced by increasing the acid strength. The sensitivity to acid strength is especially important for intermediates with ionic character. $^{64}$

The adsorption states of isobutene have received considerable interest. Upon isobutene protonation, either a tertiary butyl carbenium or a tertiary butoxide is formed. ${ }^{24,68-72}$ Tuma and Sauer were the first to include entropy effects to periodic PBE calculations on H-FER. ${ }^{68}$ They assessed the importance of the entropy effect in comparing stability differences at finite temperatures. At temperatures of $120 \mathrm{~K}$ or higher, the tertbutyl carbenium ion was shown to be more stable than the tertbutoxide. $^{68,69}$ This observation was later confirmed for a set of different zeolites by Nguyen et al. ${ }^{70}$ Dai et al. obtained evidence for the existence of a tert-butyl carbenium ion in a combined computational and spectroscopy study. ${ }^{72}$

Recently, we investigated the nature of linear and branched $\mathrm{C}_{4}$ and $\mathrm{C}_{5}$ intermediates in $\mathrm{H}-\mathrm{ZSM}-5$ at reaction conditions using a combination of static DFT calculations and molecular dynamics simulations. $^{27,28}$ For the linear species, alkoxides and $\pi$ complexes were shown to be stable intermediates at low temperature $(323 \mathrm{~K})$. At a higher temperature of $773 \mathrm{~K}$, though, alkoxides are very unstable and become short-lived inside the zeolite pores. Most modeling studies performed so far presumed the existence of alkoxide species even at high cracking temperatures, ${ }^{50,58,73-75}$ whereas our modeling efforts point toward the importance of carbenium ions at operating conditions for catalytic cracking. ${ }^{27,28}$ For the branched species, the tert-butyl carbenium ion was identified as the most stable intermediate, at both low and high temperature. Tertiary alkoxides were shown to be unstable, even at low temperature. $^{27,28}$

Alkene cracking occurs through a complex network of oligomerization, isomerization, $\mathrm{H}$-transfer, and cracking reactions. $\beta$-Scission of carbenium ions is generally accepted as the olefin cracking mechanism on solid catalysts. ${ }^{3,11,56,76-78}$ Upon $\beta$-scission, a free alkene and a smaller chemisorbed carbenium ion are formed. These primary products can also be subject to further alkylations and subsequent cracking. ${ }^{12}$ Fast isomerizations prior to the cracking reactions allow the formation of several carbenium ion types (primary, secondary, and tertiary) with different relative stabilities. ${ }^{12,56,76} \beta$-Scission reactions are therefore often classified according to the carbocation type involved in the reactant and product state (vide infra).

Several experimental studies focused on characterizing and predicting the olefin cracking product distribution. ${ }^{75,79-88}$ Standl et al. developed a single-event kinetic model capable of correctly estimating olefin cracking selectivities. ${ }^{85,86,89}$ Rate coefficients for each $\beta$-scission mode were considered to be independent of the chain length. ${ }^{89}$ Nevertheless, Buchanan et al. ${ }^{12}$ showed that $\mathrm{C}_{5}-\mathrm{C}_{8}$ olefin cracking rates over H-ZSM-5 at 
Scheme 2. Adsorbed $\pi$-Complex and Carbenium Ion Intermediates of the Linear, Monobranched, and Multibranched $\mathrm{C}_{4}-\mathrm{C}_{8}$ Alkenes

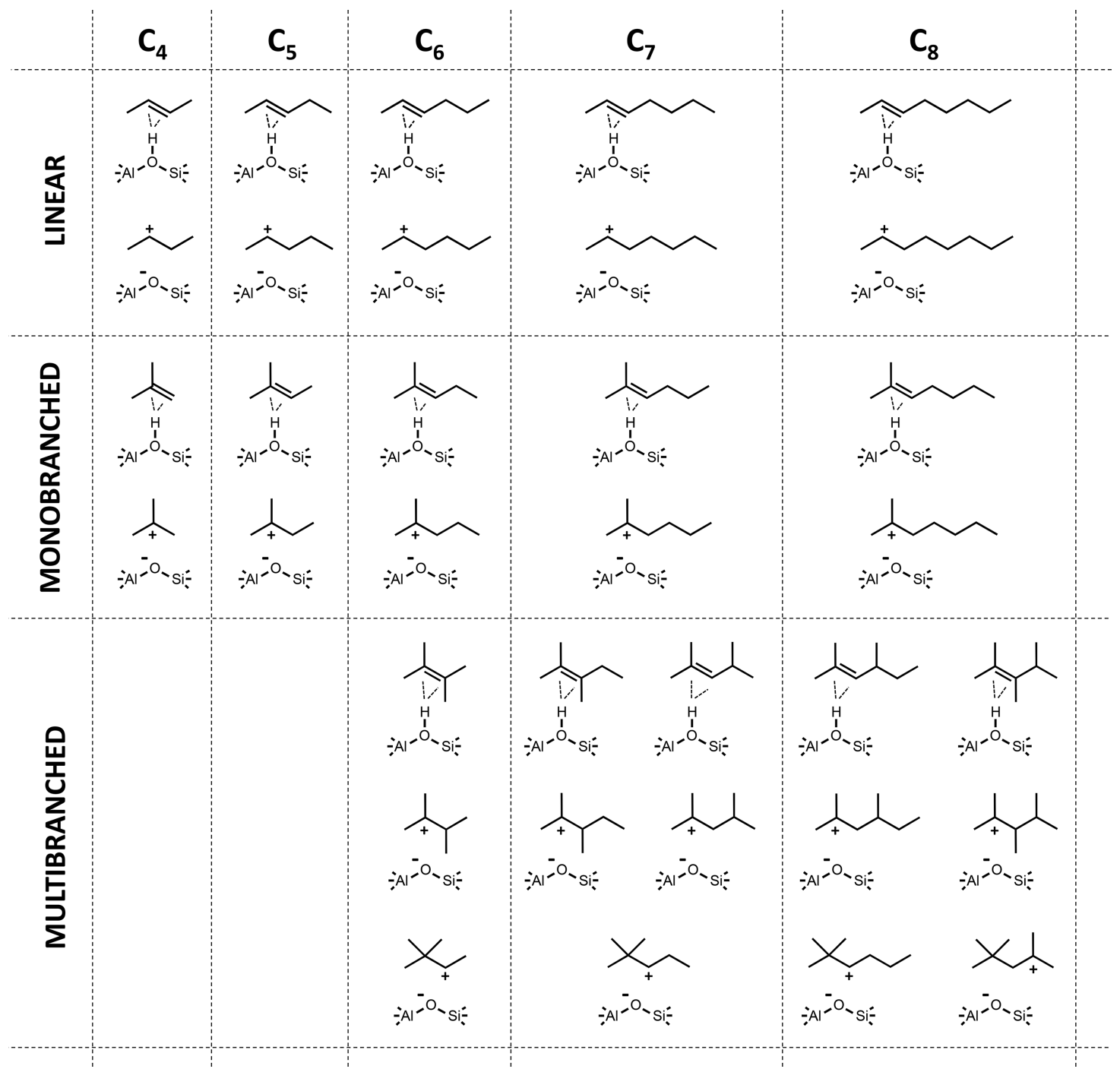

$783 \mathrm{~K}$ increase with carbon number. For longer olefins, the number of available isomers becomes larger; hence, more energetically favorable $\beta$-scission modes, involving branched, tertiary carbocations, are accessible. ${ }^{12}$ However, pore size restrictions in H-ZSM-5 may prevent the formation of highly branched isomers. $12,75-77,90-95$

In previous modeling studies, ${ }^{45,58,73,74,96}$ alkene cracking pathways have mainly been investigated with static DFT calculations. For $\mathrm{C}_{6}-\mathrm{C}_{8}$ olefin cracking in H-ZSM-5, Bhan and co-workers found that activation energies are determined primarily by the substitution order of the transition state and to a lesser extent by the substitution order of the reactant. ${ }^{74}$ The highest activation energies were observed for $\beta$-scission modes involving a transition to a primary carbocation, while the lowest are found for $\beta$-scissions with a transition to a tertiary carbocation. However, the static modeling approach, considers only a single adsorbate configuration on the potential energy surface, while the energy surface for alkene adsorption is quite flat and contains many nearly isoenergetic local minima. ${ }^{28}$ Also, at high temperature, entropy contributions may be underestimated considerably. ${ }^{16,19,97,98}$ Many studies a priori postulated stable alkoxide intermediates as cracking reactants ${ }^{58,96,73,74}$ and deduced the governing cracking modes based on the stability of alkoxides and intrinsic $\beta$-scission barriers determined from static DFT calculations.

In this work, we aim at gaining insight into the alkene cracking mechanism in H-ZSM-5 at operating conditions by using advanced molecular dynamics simulations. We investigate how the stability of carbenium ions in the reactant, transition and product states affect crucial $\beta$-scission rates at $773 \mathrm{~K}$, a typical cracking temperature. To obtain a proper understanding of the stability of the intermediates formed upon $\mathrm{C}_{4}-\mathrm{C}_{8}$ alkene adsorption at the Brønsted acid sites, a selection of linear, mono-, di-, and tribranched alkenes with varying chain length are investigated as depicted in Scheme 2. Primary carbenium ions are not retained due to their highly unstable nature. ${ }^{12,74,85,86} \mathrm{Ab}$ initio molecular dynamics simulations, which inherently account for entropy effects and adsorbate mobility, are carried out to determine the lifetime of the various intermediates. In a next step, this knowledge is used to study the reactivity of linear and branched $\mathrm{C}_{8}$ intermediates toward monomolecular alkene cracking. Starting from the previously identified stable intermediates we estimate the reaction kinetics at operating conditions for five specific $\beta$-scission modes (Scheme 3). Herein, we adopt the nomenclature, introduced by Weitkamp et al. ${ }^{99}$ to distinguish between the elementary $\beta$ - 
Scheme 3. Five Possible $\beta$-Scission Modes for Monomolecular $\mathrm{C}_{8}$ Alkene Cracking Pathways

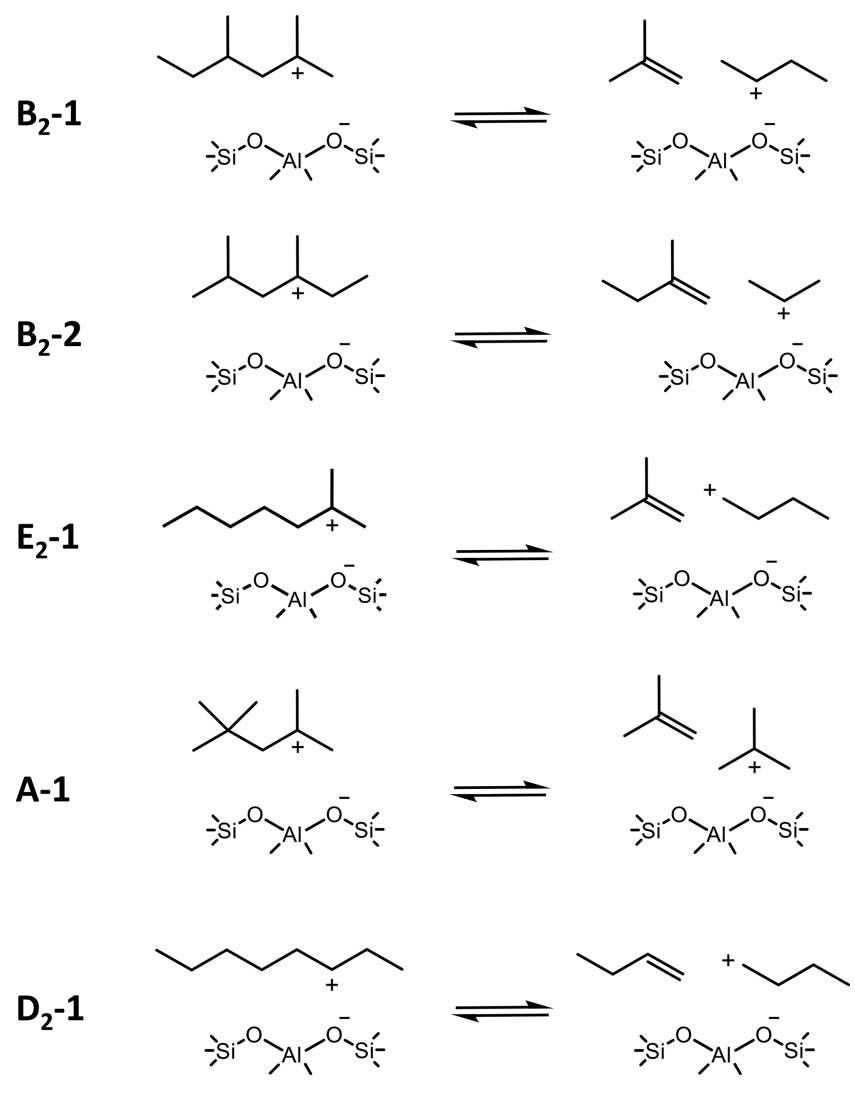

scission modes. Our approach relies on enhanced sampling molecular dynamics techniques to reconstruct the free energy profile at cracking conditions. A critical comparative assessment is made with activation energies at $0 \mathrm{~K}$, predicted by static DFT calculations. Overall, the study yields new insights into the nature and reactivity of plausible intermediates and the impact of carbenium ion stability on the cracking pathways at operating temperatures.

\section{COMPUTATIONAL METHODS}

2.1. Zeolite Model. All calculations are performed on a fully periodic model of H-ZSM-5, containing 289 atoms and a single acid site per unit cell. This way, the confinement of the zeolite pores can be properly accounted for. H-ZSM-5 exhibits the MFI topology, characterized by perpendicularly intersecting straight and sinusoidal 10-ring channels, forming a three-dimensional medium-sized pore system. A Brønsted acid site is created by substituting a $\mathrm{Si}$ atom at the $\mathrm{T} 12$ position by an $\mathrm{Al}$ atom and a charge-compensating proton. The active site is located at the intersection of the straight and sinusoidal channel, allowing maximal space for the adsorbed guest molecules. The timeaveraged dimensions of the orthorhombic unit cell are obtained from a preliminary 5 ps molecular dynamics run in the $\mathrm{NpT}$ ensemble at $773 \mathrm{~K}$ and 1 bar (cf. Table S1).

2.2. Static Calculations. To evaluate activation barriers and reaction energies for a set of $\beta$-scission reactions, static DFT calculations are employed using the Vienna Ab Initio Simulation Package (VASP 5.4.1). ${ }^{100-103}$ First, transition states for the $\beta$ scission reactions were searched by the improved dimer method. ${ }^{104}$ To localize the reactant and product states corresponding to the identified transition state, the atoms were slightly displaced along the imaginary normal mode corresponding to the transition state motion. Then, the reactant and product ions were relaxed into the ground state with the conjugate gradient method. For all calculations, the $\Gamma$-point approximation for the sampling of the Brillouin zone was applied. Each stationary state has been optimized using the gradient corrected PBE functional ${ }^{105}$ with additional Grimme D3 dispersion corrections ${ }^{106}$ and the projected augmented wave method (PAW) ${ }^{107,108}$ The plane wave kinetic energy cutoff was set to $600 \mathrm{eV}$ while the self-consistent field (SCF) convergence criterion was fixed at $10^{-5} \mathrm{eV}$. The unit cell volume was kept fixed during the geometry optimization to eliminate the effect of lattice strain and to ensure the same truncated basis set is used. Energies are reported at the PBE-D3 level to allow proper comparison with the molecular dynamics simulations. The nature of the optimized local minima and transition states was verified by a normal-mode analysis. To obtain the normal modes, the partial Hessian vibrational analysis (PHVA) (109-111 $^{-1}$ was applied on the adsorbate and an $8 \mathrm{~T}$ cluster of the framework, centered around the acid. Thermal corrections were estimated on the basis of the harmonic oscillator ( $\mathrm{HO})$ approximation. Ultimately, we determined the reaction enthalpies, entropies, and Gibbs free energies at the cracking temperature of $773 \mathrm{~K}$ using the in-house developed TAMkin software. $^{112}$

2.3. Ab Initio Molecular Dynamics Simulations. Molecular dynamics simulations were performed to assess the nature and lifetime of alkene cracking intermediates. The dynamic behavior of some intermediates may depend on the reaction conditions such as temperature and pressure. In contrast to static calculations, framework flexibility and entropy effects can be inherently accounted for. All ab initio MD simulations have been carried out with the CP2K software package (CP2K 3.0), ${ }^{113}$ using the revPBE ${ }^{114}$ level of theory with additional Grimme D3 dispersion corrections, ${ }^{106}$ a DZVP basis set and GTH pseudopotentials. ${ }^{115}$ A combination of Gaussian and plane waves $(\mathrm{GPW})^{116,117}$ basis functions with a cutoff energy of $320 \mathrm{Ry}$ are used. The self-consistent field (SCF) convergence criterion was set at $10^{-6} \mathrm{eV}$. The time step for integrating the equations of motion was set at $0.5 \mathrm{fs}$. The simulations were performed in the NVT ensemble at a temperature of $773 \mathrm{~K}$, controlled by a chain of five NoséHoover thermostats. ${ }^{118,119}$

After an equilibration run of $5 \mathrm{ps}$, a production run of $100 \mathrm{ps}$ was performed to obtain a sufficient sampling of the phase space. When isomerizations or other rearrangements occurred in the equilibration run or at the beginning of the production run, the simulation was repeated thrice with reinitialized starting conditions. This will ensure that the observed transition is not merely a rare event, caused by the random choice of initial velocities.

The identification of the various possible intermediates that are sampled in the MD simulation was computed on the basis of a distance criterion. The adsorbate is classified as a physisorbed $\pi$-complex if the distances between the acid proton and the double bond carbon atoms are both smaller than $2.85 \AA$; otherwise, it is considered as a van der Waals complex. The sampled state is considered a chemisorbed carbenium ion if all distances between a hydrogen and an acid site oxygen $\left(\mathrm{O}_{z}\right)$ are larger than 1.25 $\AA$. To track the position of the positive charge in the carbenium ion state, the trivalent carbon atom is identified by assigning each hydrogen to the closest carbon. An alkoxide is 
sampled if a covalent $\mathrm{C}-\mathrm{O}_{z}$ bond with the framework smaller than $1.9 \AA$ is formed.

2.4. Metadynamics Simulations. The probability of sampling rare events, like isomerization or cracking reactions these activated transitions, accelerated sampling techniques are required. Metadynamics simulations (MTD) are applied to assess the free energy difference between the elusive intermediates. $^{120,121}$ We applied the same procedure as described in ref 27 . The sampling of specific reaction paths on the free energy surface requires the definition of a collective nate. ${ }^{120-122}$ MTD simulations are run with the same settings as for the MD simulations, i.e., in the NVT ensemble at actual cracking conditions $(773 \mathrm{~K})$. At regular instants during the simulation, Gaussian hills are spawned along the collective variable which is defined based on coordination numbers $(\mathrm{CN})$ :

$$
\mathrm{CN}=\sum_{i, j} \frac{1-\left(r_{i j} / r_{0}\right)^{n n}}{1-\left(r_{i j} / r_{0}\right)^{n d}}
$$

in which the sum runs over two sets of atoms $i$ and $j$ with $r_{i j}$ the interatomic distance between atoms $i$ and $j$ and $r_{0}$ a reference distance. The parameters $n n$ and $n d$ are set at 6 and 12, respectively. All simulations in this work use a single CV (1D MTD): $\mathrm{CN}\left(\mathrm{C}_{\mathrm{h}}-\mathrm{H}_{\mathrm{h}}\right)-\mathrm{CN}\left(\mathrm{H}_{\mathrm{h}}-\mathrm{O}_{z}\right)$ to describe the proton transfer from the zeolite $(\mathrm{z})$ to the hydrocarbon $(\mathrm{h})$, shown in Scheme 4. A reference distance of $1.25 \AA$ is selected which is close to typical transition state bond distances for (de)protonation reactions.

Scheme 4. Collective Variable (Difference of Coordination Numbers) Used in the Metadynamics Simulations of the Protonation of a 2-Alkene into a 2-Alkyl or 3-Alkyl Carbenium Ion

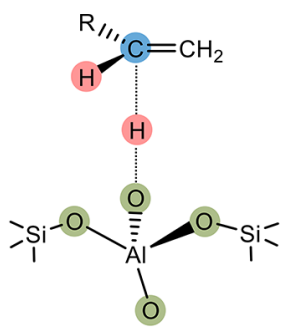

$\left.\mathrm{CN}\left(\mathrm{C}_{5}-\mathrm{H}_{\mathrm{n}}\right)-\mathrm{CN}\left(\mathrm{H}_{5}\right)-\mathrm{O}_{2}\right)$ in regular MD is typically very low. To enhance the sampling of variable $(\mathrm{CV})$, uniquely describing the reaction coordi-

$$
\begin{aligned}
& \Delta G_{\mathrm{fwd}}^{\ddagger}=G_{\mathrm{max}, \mathrm{TS}}-G_{\mathrm{min}, \mathrm{R}} \\
& \Delta G_{\mathrm{bwd}}^{\ddagger}=G_{\text {max }, \mathrm{TS}}-G_{\mathrm{min}, \mathrm{P}}
\end{aligned}
$$

Additional technical details on the MTD simulations can be found in Section S2 of the SI.

2.5. Umbrella Sampling. In metadynamics simulations, the reaction profile is obtained through multiple crossings of the activated transition state, separating the reactant and product valley. Accordingly, this requires the existence of clearly defined, stable minima to allow the forward and backward reactions to be properly sampled. However, in the case of $\beta$-scission reactions the formed reaction products are often unstable and prone to rapid rearrangements. Since these reorganizations are not uniquely described by the selected collective variables, the sampling of the backward reaction may be hindered. Therefore, the more robust umbrella sampling (US) method ${ }^{123,124}$ is used to determine the free energy profiles for the selected alkene cracking reactions. With this technique, the conformational space is subdivided into a number of windows along the reaction coordinate that are sampled individually during the free energy simulations. To the best of our knowledge, this is the first application of umbrella sampling to study zeolite-catalyzed reactions.

All umbrella sampling simulations have been performed with $\mathrm{CP} 2 \mathrm{~K}$ as MD engine, interfaced with the PLUMED module. ${ }^{125}$ The protonation of a linear alkene into a carbenium ion is sampled using a coordination number between the acid site oxygen atoms and the hydrocarbon hydrogen atoms, $\mathrm{CN}\left(\mathrm{O}_{z^{-}}\right.$ $\mathrm{H}_{\mathrm{h}}$ ) as collective variable (Scheme $\left.5 \mathrm{a}\right)$. To properly describe the

Scheme 5. Collective Variables (Coordination Numbers) Used during the Umbrella Sampling Simulations of (a) the Protonation of 2-Alkenes and (b) the $\beta$-Scission of a Carbenium Ion

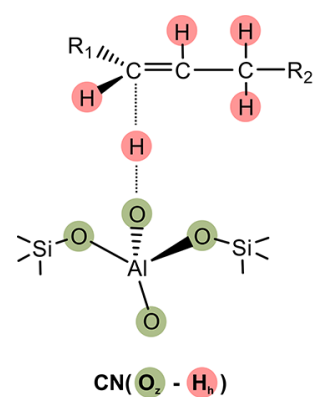

(a)
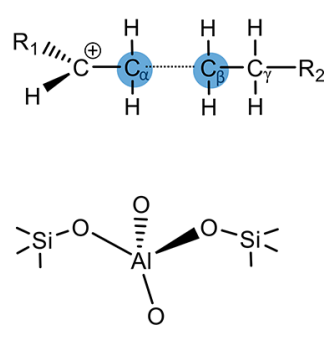

$\operatorname{CN}\left(C_{\alpha}-C_{\beta}\right)$

(b)
To ensure a clear distinction between reactant, product, and transition state, isomerizations were prevented; hence, the same carbon atom would get protonated each time. To this end, the simulation is constrained to the particular area of interest by applying quadratic walls. Hills with a height of $2 \mathrm{~kJ} / \mathrm{mol}$ and a width of 0.035 are added every 100 time steps. Upon each recrossing of the barrier, the hill height was reduced by half to improve the convergence of the free energy profile. The latter is reconstructed on the basis of the sum of all spawned Gaussian hills along the reaction coordinate. The simulations were continued until the addition of extra hills no longer changed the resulting free energy profile. Finally, activation free energy barriers $\Delta G^{\ddagger}$ were computed as the difference between the maximal free energy in the transition state (TS) region and the minimal free energy in the reactant $(R)$ or product $(P)$ valley. cracking reaction, a coordination number between all atoms involved in the $\beta$-scission; e.g., the carbon atoms in $\alpha$ and $\beta$ position of the positive charge, $\mathrm{CN}\left(\mathrm{C}_{\alpha}-\mathrm{C}_{\beta}\right)$, is defined as collective variable (Scheme $5 b)$. The total range of the collective variable, $q$, is divided into a number of windows. For each window, biased MD simulations are run in parallel. The initial configuration for each window is randomly selected from a moving bias potential simulation, describing the entire collective variable range of the reaction. To ensure a sufficient sampling along the entire reaction coordinate, harmonic bias potentials, centered around the equilibrium value $q_{0}$, are employed.

$$
U_{\mathrm{b}}(q)=\frac{\kappa}{2}\left(q-q_{0}\right)^{2}
$$




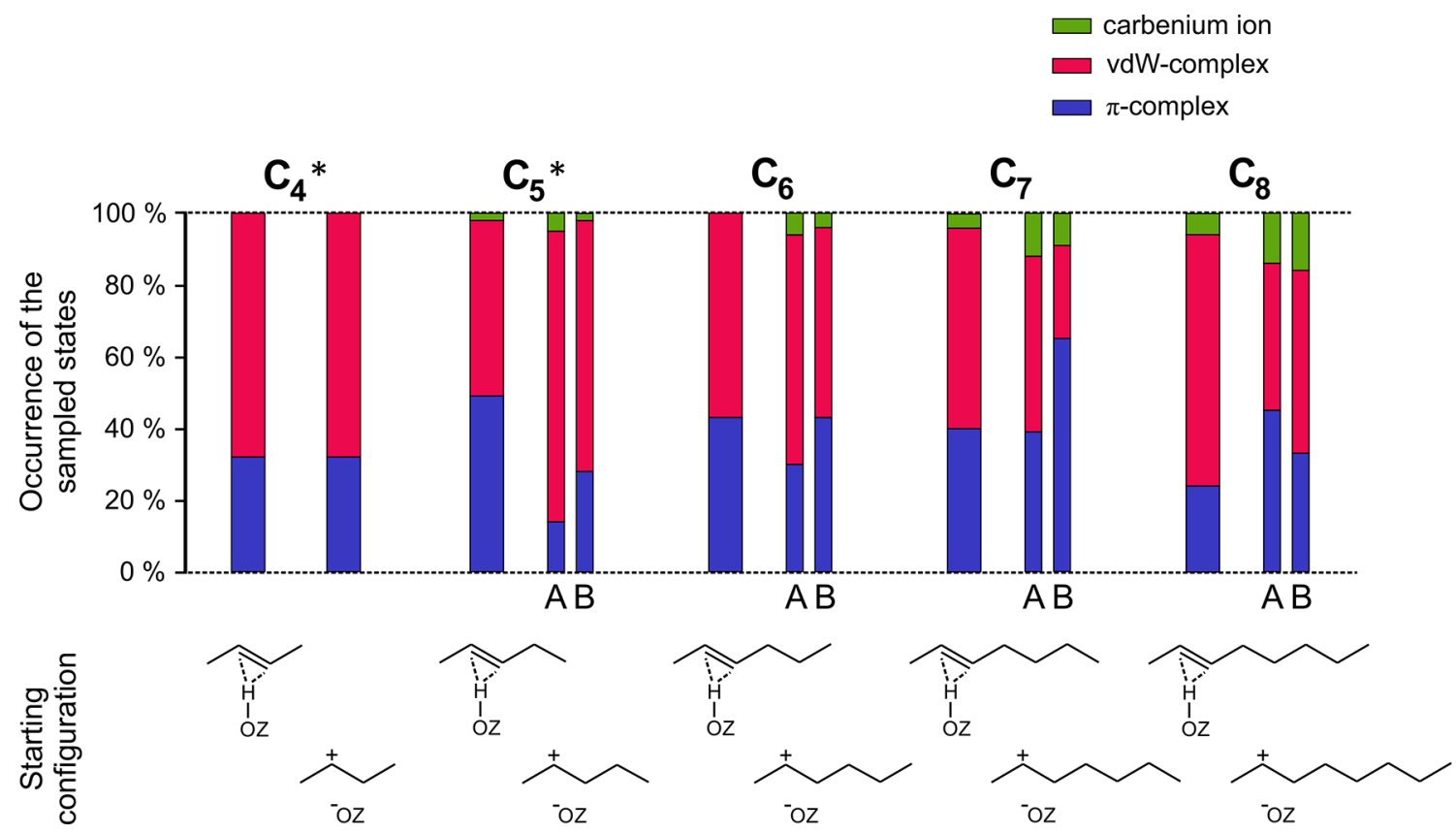

Figure 1. Fractions of the sampled intermediates during the $100 \mathrm{ps} \mathrm{MD}$ simulations on the linear $\mathrm{C}_{4}-\mathrm{C}_{8}$ species at $773 \mathrm{~K}$, with either the $\pi$-complex or carbenium ion as starting configuration. Two independent carbenium ion simulations are denoted as A and B (*data taken from ref 27).

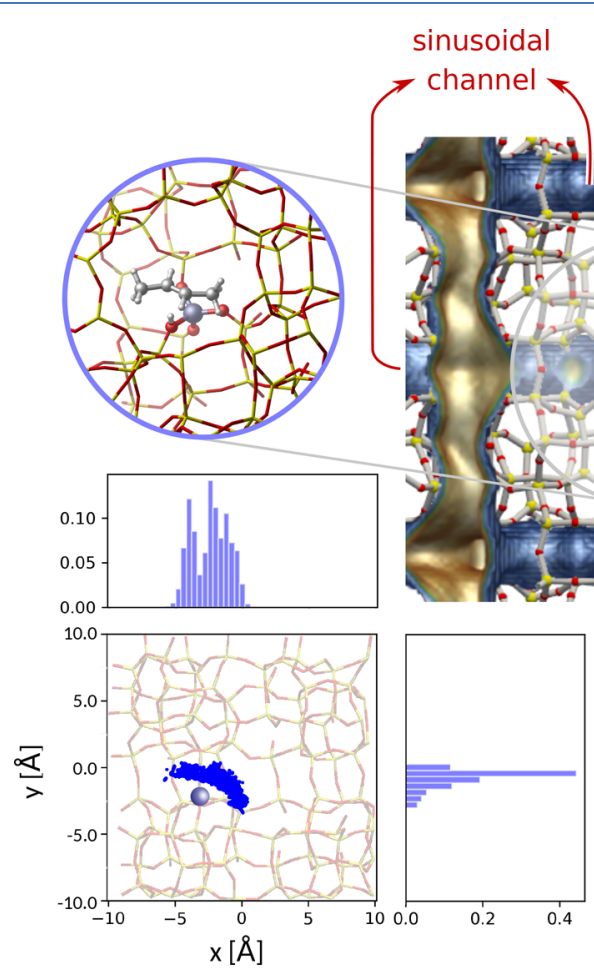

(a) $\pi$-complex straight

\section{channel}
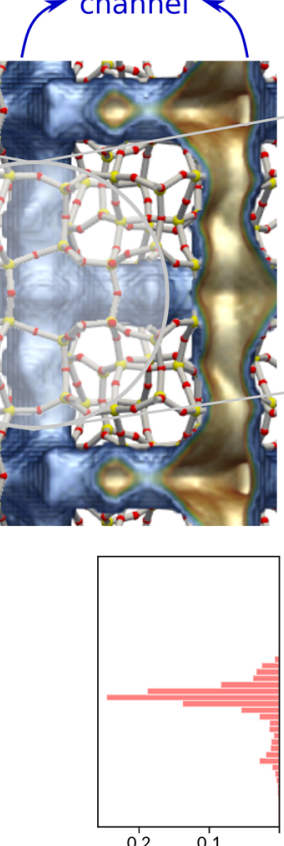

(b) vdW-complex

Figure 2. Scatter plot of the center of mass of (a) the 2-butene $\pi$-complex and (b) the 2-butene van der Waals complex inside the channel system of $\mathrm{H}$ ZSM-5, projected on the $x y$ plane. The purple sphere represents the location of the acid site.

The free energy difference in each window can be obtained from the sampling distribution along the specified collective variable. The weighted histogram analysis method (WHAM), ${ }^{126,127}$ implemented by the Grossfield Laboratory, ${ }^{128}$ is applied to reconstruct the free energy profiles by combining the results of each window. An overview of the used collective variables, the umbrella positions and bias strengths in the US simulations can be found in Table S2 of the SI.

\section{RESULTS AND DISCUSSION}

3.1. Influence of Chain Length on Carbenium Ion Stability. The stability of adsorbed alkene intermediates isnext to temperature and branching-influenced by the chain 


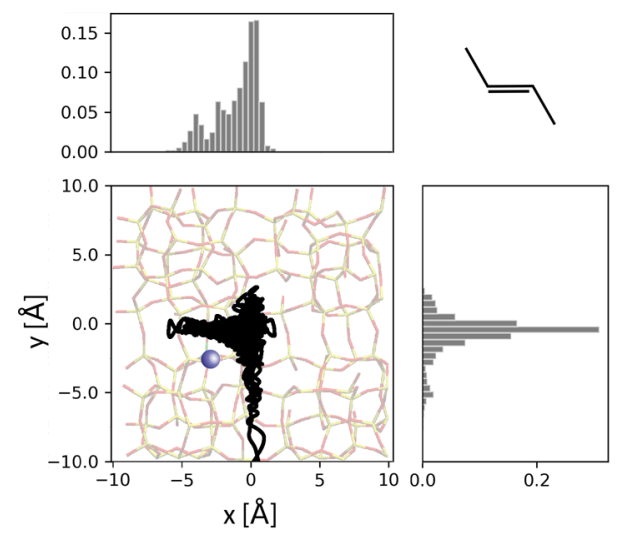

(a)

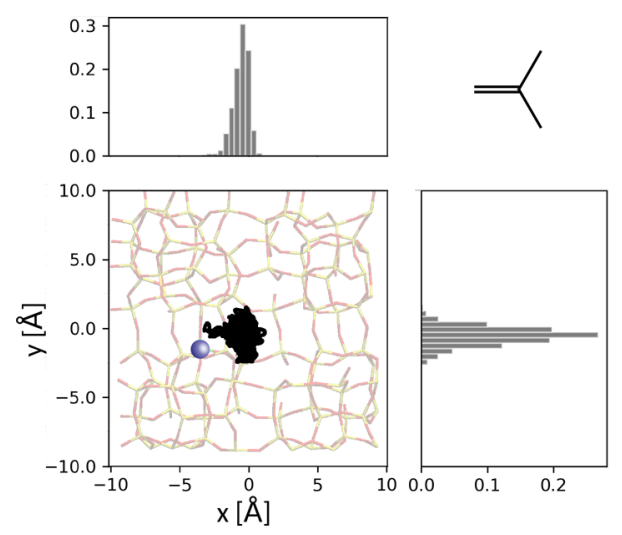

(c)

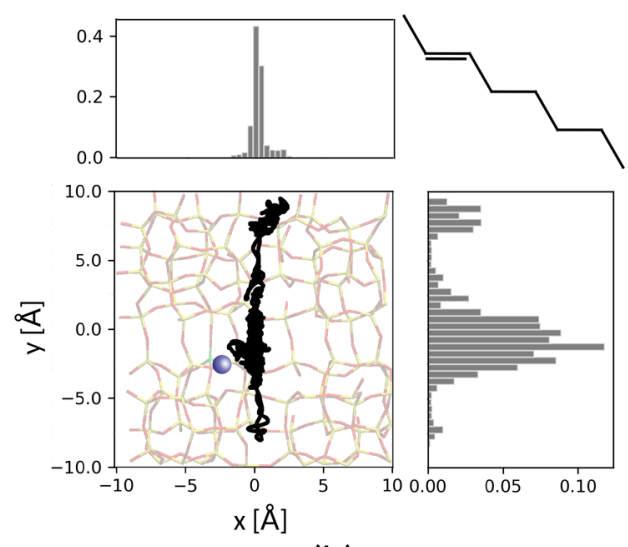

(b)

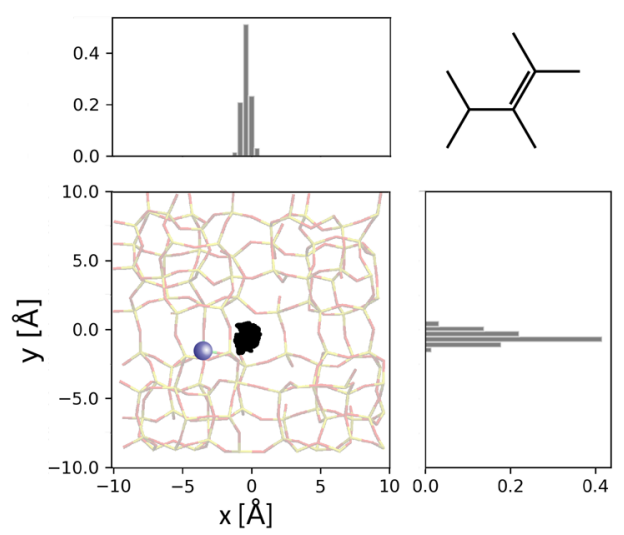

(d)

Figure 3. Scatter plot of the center of mass of (a) 2-butene, (b) 2-octene, (c) isobutene, and (d) 2,3,4-trimethyl-2-pentene inside the channel system of H-ZSM-5, projected on the $x y$ plane. The purple sphere represents the location of the acid site.

length of the adsorbate. Longer alkyl chains are expected to adsorb more strongly due to the increased contribution of dispersion interactions. Entropy is also expected to become more important for longer chains. ${ }^{50}$ To assess the impact of the chain length effect, we investigated the dynamic behavior of a series of linear and branched $\mathrm{C}_{4}-\mathrm{C}_{8}$ alkene intermediates (see Scheme 2) with MD simulations at $773 \mathrm{~K}$. In our previous work, we showed that both linear and branched pentoxides are unstable inside the zeolite pores at elevated temperature. Instead, they immediately transform into carbenium ions. ${ }^{27,28}$ Based on these observations, we can safely assume that longer alkoxides will not exist either. Therefore, we only performed MD simulations starting from the physisorbed alkene $\pi$-complex and the chemisorbed carbenium ion.

3.1.1. Linear Alkenes. For the linear alkenes, we considered the homologous series of 2-alkenes, ranging from 2-butene to 2octene. In the course of the simulations, spontaneous alkene protonation and deprotonation reactions are occasionally observed. Since the transitions between neutral alkene and carbenium ion species are sampled in regular MD simulations, we can evaluate their relative stability by comparing the lifetime of these intermediates. Figure 1 summarizes the resulting time fractions during which the alkene $\pi$-complex, the alkene van der Waals complex, and the carbenium ion are sampled in the various $\mathrm{MD}$ simulations. Starting from the carbenium ion configuration, two independent simulations (A and B) are conducted.
Figure 1 reveals some trends which are specific for the linear alkenes. First, the combined fractions of the physisorbed states ( $\pi$-complex and van der Waals complex) range from 86 to $100 \%$ in every simulation, showing that the neutral alkene is significantly more stable than the carbenium ion for the entire $\mathrm{C}_{4}-\mathrm{C}_{8}$ range. The van der Waals complex is slightly favored over the $\pi$-complex, but frequent transitions (500-1000 per simulation) take place between the two physisorbed states. No clear trend with increasing chain length can be identified for the ratio of $\pi$-complex to van der Waals complex. Despite the additional stabilization from the $\pi$-H interaction in the $\pi$ complex, the more loosely bound van der Waals complex is entropically favored at high temperature. To study the mobility and the entropic contributions of the various species in the zeolite pores in depth, we postprocessed our MD data to determine for each adsorbate the translational part to the entropy in the zeolite pore system and to construct 2D scatter plots visualizing the mobility of the various species and $1 \mathrm{D}$ probability distributions along the $x, y$, and $z$ directions. The $y$ direction corresponds to the direction of the straight channel, whereas the direction of the sinusoidal channel lies in the $x z$ plane. More details are given in Section S5 of the SI. Furthermore, for 2-butene and 2-octene, we disentangled the contributions from the $\pi$-complex and van der Waals complex. The resulting mobility plots for 2-butene are shown in Figure 2.

It is immediately clear that the van der Waals complex has a much larger mobility compared with the $\pi$-complex and travels 
along relatively long paths in the straight channel of the zeolite during the ca. $70 \mathrm{ps}$ in which the van der Waals complex is sampled. The entropic stabilization of the van der Waals complex due to translational movements in the straight channel is about $7 \mathrm{~kJ} / \mathrm{mol}$ higher than the entropic stabilization of the $\pi$ complex. The translational entropy contributions for all species are summarized in Table S5. Similar mobility plots for 2-butene, 2-octene, isobutene, and 2,3,4-trimethyl-2-pentene are shown in Figure 3. The distinction between the various adsorbed states has not been made anymore, as the latter exist for the majority of time in their carbenium ion state (vide infra). The mobility of 2butene and 2-octene are substantially different. 2-butene enters more deeply into the sinusoidal channel, whereas the longer 2octene chain prevents the adsorbate to enter the sinusoidal channel efficiently in a simulation time span of 90 ps. Instead, 2octene travels further along the straight channel of the zeolite, which yields an additional entropic stabilization of about $14 \mathrm{~kJ} /$ mol for the 2-octene van der Waals complex compared to the $\pi$ complex.

Second, (de)protonation reactions occasionally occur during the course of the simulations. The probability of sampling a protonated alkene is small but not negligible at higher chain lengths. Approximate lifetimes for the various carbocations are shown in Figure S5. For longer alkenes, the maximum carbenium ion lifetime increases due to inductive and hyperconjugative stabilization which allow for a better accommodation of the positive charge. During the sampling of the cationic state, low-barrier hydride shifts are frequently observed. This effect also contributes to the enhanced stabilization of longer alkyl cations. While only two carbon atoms can bear the positive charge in a $n$-butyl carbenium ion, the charge can effectively be delocalized over six carbon atoms in an octyl carbenium ion. Isomerization occurs either via a 1,2-hydride shift, a 1,3-hydride shift, or a 1,5-hydride shift for the longer alkyl chains. The positive charge distribution among the carbon atoms of each alkyl carbenium ion is visualized in Figure 4. Owing to the short
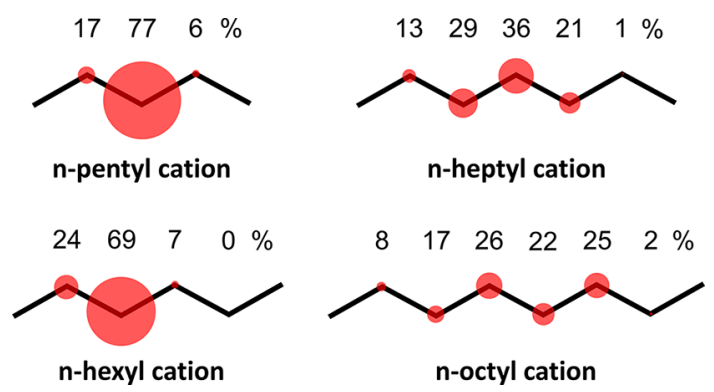

Figure 4. Delocalization of the positive charge (\%) along the alkyl chain during the carbocation sampling of the 2-alkyl carbenium ion simulations (simulation A and B combined).

sampling times of the cationic state, the reported distributions do not represent the equilibrium. Nevertheless, they clearly show that the positive charge preferably resides on the central carbon atoms of the chain.

The transformation of a physisorbed complex into a carbenium ion is an activated process, even at higher temperatures. Cracking modes starting from linear carbenium ions $\left(D_{2}\right.$ mode, see Scheme 3 ) would first have to overcome the barrier for carbenium ion formation. To quantify the free energy difference between the carbenium ion and the physisorbed alkene more accurately and to determine free energies of activation for their interconversion, metadynamics simulations are carried out for the protonation of 2 -alkenes.

The uncertainty on free energy barriers from a single metadynamics simulation can be quite large. ${ }^{27}$ Therefore, to obtain reliable free energy estimates, each simulation was repeated 5 times and the average and spread on the resulting activation barriers and reaction free energies are reported in Table 1. The 2-alkene protonation barrier $\left(\Delta G_{\text {fwd }}^{\ddagger}\right)$ has a

Table 1. Average Free Energy Activation Barriers and Reaction Free Energies at $773 \mathrm{~K}$ for the Protonation of the Linear $\mathrm{C}_{4}-\mathrm{C}_{8}$ Alkenes into the Corresponding Carbenium Ions from Metadynamics Simulations ${ }^{a}$

\begin{tabular}{|c|c|c|c|c|}
\hline & & $\begin{array}{c}\Delta G^{\dagger}{ }_{\mathrm{fwd}} \\
(\mathrm{kJ} / \mathrm{mol})\end{array}$ & $\begin{array}{c}\Delta G_{\text {bwd }}^{\ddagger} \\
(\mathrm{kJ} / \mathrm{mol})\end{array}$ & $\underset{(\mathrm{kJ} / \mathrm{mol})}{\Delta G_{\mathrm{r}}}$ \\
\hline $\mathrm{C}_{4}$ & 2 -butene $\rightarrow 2$-butyl cation* & $52 \pm 4$ & $23 \pm 2$ & $26 \pm 5$ \\
\hline \multirow[t]{2}{*}{$\mathrm{C}_{5}$} & 2 -pentene $\rightarrow 2$-pentyl cation $*$ & $49 \pm 4$ & $26 \pm 2$ & $23 \pm 4$ \\
\hline & 2 -pentene $\rightarrow 3$-pentyl cation $*$ & $49 \pm 4$ & $22 \pm 6$ & $27 \pm 5$ \\
\hline \multirow[t]{2}{*}{$\mathrm{C}_{6}$} & 2-hexene $\rightarrow$ 2-hexyl cation & $48 \pm 3$ & $30 \pm 4$ & $18 \pm 1$ \\
\hline & 2-hexene $\rightarrow$ 3-hexyl cation & $46 \pm 3$ & $30 \pm 4$ & $17 \pm 7$ \\
\hline \multirow[t]{2}{*}{$\mathrm{C}_{7}$} & 2-heptene $\rightarrow$ 2-heptyl cation & $47 \pm 3$ & $23 \pm 4$ & $24 \pm 2$ \\
\hline & 2-heptene $\rightarrow 3$-heptyl cation & $47 \pm 3$ & $38 \pm 3$ & $9 \pm 4$ \\
\hline \multirow[t]{2}{*}{$\mathrm{C}_{8}$} & 2-octene $\rightarrow$ 2-octyl cation & $50 \pm 3$ & $26 \pm 5$ & $23 \pm 7$ \\
\hline & 2-octene $\rightarrow 3$-octyl cation & $48 \pm 3$ & $38 \pm 3$ & $10 \pm 3$ \\
\hline
\end{tabular}

constant value of $50 \mathrm{~kJ} / \mathrm{mol}$ approximately, regardless of the chain length. The free energy barrier for deprotonation $\left(\Delta G_{\text {bwd }}^{\ddagger}\right)$ is systematically lower than the protonation barrier. The relatively low deprotonation barriers, combined with the overall higher stability of the alkenes are in line with the relatively small fraction of the time in which carbenium ions are sampled in the MD simulations. The free energy differences $\left(\Delta G_{\mathrm{r}}\right)$ corroborate the observation that the positive charge is better accommodated at central chain positions. Both the $\mathrm{C}_{4}$ and $\mathrm{C}_{5}$ carbenium ions are around $25 \mathrm{~kJ} / \mathrm{mol}$ higher in free energy than the corresponding alkenes. For the $\mathrm{C}_{7}$ and $\mathrm{C}_{8}$ species, a clear distinction can be made between the 2-alkyl and 3-alkyl carbenium ion. While the 2 -alkyl carbenium ions are about 21 $\mathrm{kJ} / \mathrm{mol}$ higher in free energy than the corresponding 2-alkenes, the 3 -alkyl carbenium ions are only $10 \mathrm{~kJ} / \mathrm{mol}$ less stable than the 2-alkenes.

In principle, free energy differences between the various adsorbed states can also be roughly deduced from regular MD simulations provided that sufficient transitions are sampled. The free energy differences between the linear alkenes and carbenium ions from the regular $\mathrm{MD}$ simulations are presented in Table S8 in SI. Although the carbenium ion sampling time is rather short, the $\Delta G$ estimates from regular MD and MTD simulations are in good agreement. For all $\mathrm{C}_{5}$ to $\mathrm{C}_{8} \mathrm{MD}$ simulations with a sufficiently large carbenium ion sampling time, the alkene/carbenium ion free energy differences lie in the same range as those predicted by the MTD simulations.

3.1.2. Branched Alkenes. Branched alkenes contain tertiary carbon atoms which may significantly impact the stability order of the intermediates. In earlier work, we have shown that the tertiary carbenium formed upon isobutene and 2-methyl-2butene adsorption is a stable intermediate at $773 \mathrm{~K} .{ }^{27}$ In this section, we evaluate the influence of chain length on $\mathrm{C}_{4}-\mathrm{C}_{8}$ alkenes with one or more methyl branches.

Figure 5 shows the fractions of the states sampled in MD simulations at $773 \mathrm{~K}$ for the monobranched 2-methyl-2-alkenes 


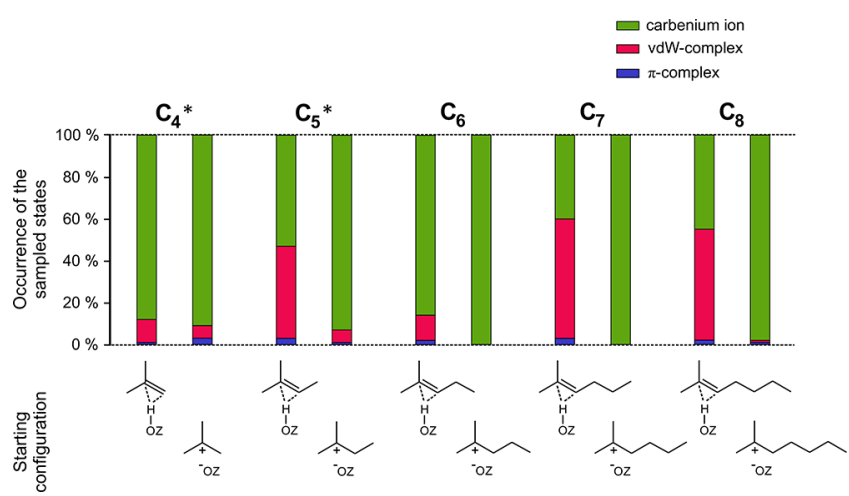

Figure 5. Fractions of the intermediates sampled during the 100 ps MD simulations on the monobranched $\mathrm{C}_{4}-\mathrm{C}_{8}$ species at $773 \mathrm{~K}$, either with the $\pi$-complex or carbenium ion as starting configuration (*data taken from ref 27).

(cf. Scheme 2). Irrespective of chain length, carbenium ions from branched alkenes are clearly much more stable than from linear alkenes. In contrast to the linear alkenes, no clear trend with higher carbon number can be discerned. Throughout the largest part of the simulations, tertiary carbenium ions are sampled. Hydride shifts to secondary carbenium ions are rarely observed. The positive charge resides almost exclusively on the tertiary carbon atom, reflecting the higher stability of tertiary carbenium ions. This is also evidenced by the lifetime of these carbenium ions across the different simulations, depicted in Figure S6. The observed maximum lifetime of the tertiary carbenium ions is much larger than for any of the linear, secondary carbenium ions.

All branched 2-methyl-2-alkenes are also stable, although the physisorbed alkene fraction is much smaller compared to linear alkenes. The $\pi$-complex comprises only a very small fraction, indicating that the van der Waals complex is by far the most stable physisorbed state. Clearly, the bulkier branched alkenes are sterically more hindered making it more difficult to approach the acid site to form the $\pi$-complex.

Similar observations can be made for $\mathrm{C}_{6}-\mathrm{C}_{8}$ alkene isomers with multiple side chains. Figure 6 displays the fractions of the sampled intermediates in MD simulations on a set of di- and tribranched alkenes at $773 \mathrm{~K}$. Carbenium ions are again the dominating intermediates due to the presence of tertiary carbon atoms. The smallest tribranched 2,3,4-trimethyl-2-pentyl species

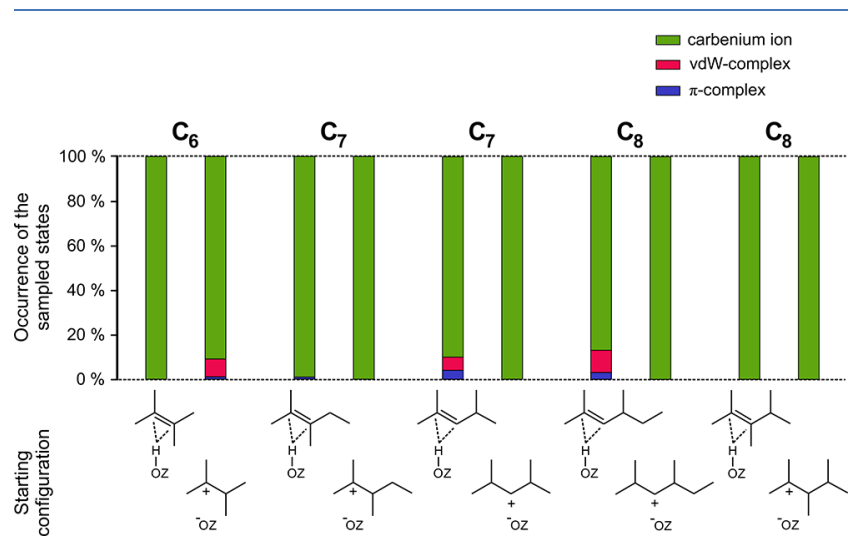

Figure 6. Fractions of the sampled intermediates during the $100 \mathrm{ps} \mathrm{MD}$ simulations on the multiple branched $\mathrm{C}_{6}-\mathrm{C}_{8}$ species at $773 \mathrm{~K}$, either with the $\pi$-complex or carbenium ion as starting configuration. exists solely as carbenium ion, regardless of the starting configuration. Immediate protonation takes place at the beginning of the alkene simulation. Despite the presence of neighboring tertiary carbon atoms, almost no $\mathrm{H}$-shift isomerizations are observed for the multiple branched chains. The barrier for isomerization between different tertiary carbenium ions appears to be much higher than for secondary carbenium ions. In contrast to the linear chains, for which isomerization partly provided stabilization, tertiary carbenium ions are stable, regardless of the positive charge position along the chain. All carbenium ions for the branched species remain positioned at the intersection of the straight and sinusoidal channel as is clear from the mobility plots for isobutene and 2,3,4-trimethyl-2pentene, shown in Figure 3c,d respectively. Due to the cationic nature, these species remain relatively close to the positive acid site to avoid excessive charge separation.

For $\mathrm{C}_{6+}$ alkenes, geminal methyl substituted intermediates, i.e., with a quaternary carbon atom, can also be formed. However, our MD simulations indicate that these species are extremely unstable. In all simulations of the homologous series of 2,2-dimethyl-3-alkyl secondary carbenium ions (Scheme 2), immediate rearrangements are observed. The 2,2-dimethyl-3butyl carbenium ion instantly isomerizes via a methyl shift into the 2,3-dimethyl-2-butyl carbenium ion. The larger 2,2dimethyl-3-pentyl and 2,2-dimethyl-3-hexyl carbenium ions both stabilize through a rapid $\mathrm{H}$-shift, followed by a $\beta$-scission reaction, forming the tert-butyl carbenium ion and propene/ butene. Opposed to these extremely reactive secondary carbenium ions, the tertiary and highly branched 2,4,4trimethyl-2-pentyl carbenium ion remains stable for the entire simulation time. However, previous studies have reported that the formation of species with geminal methyl substitutions or more than two methyl substitutions is prohibited by the pore dimensions. $^{76,85,93-95}$

In conclusion, at typical cracking temperatures, linear alkenes are predominantly found as $\pi$-complex or van der Waals complex in the zeolite pores. Linear carbenium ions are shortliving, although their lifetime increases with chain length, since the positive charge can be delocalized over more carbon atoms. Alkenes with one or multiple branches occur almost exclusively as carbenium ions with a relatively low mobility compared to linear alkenes.

3.2. Reactivity of $\mathrm{C}_{8}$ Cracking Intermediates. $\beta$-scission of carbenium ions is widely accepted as the predominant mechanism for alkene cracking in zeolites. Next to the stability of the cationic reactants, the stability of the product cations, formed in the transition state, is a key factor determining the reactivity. ${ }^{74,75}$ From the MD analysis, physisorbed alkenes and tertiary carbenium ions were identified as the most stable species for linear and branched alkenes respectively. In this section, the reactivity of the governing $\mathrm{C}_{8}$ intermediates toward catalytic cracking of different $\beta$-scission modes is assessed. Three possible cracking modes for the highly stable tertiary carbenium ion reactants are considered, as shown in Scheme 3: a transition from a tertiary carbenium to a primary carbenium ion (mode $\mathrm{E}_{2}$ ), to a secondary carbenium ion (mode $\mathrm{B}_{2}$ ) or to a tertiary carbenium ion (mode A). For linear alkenes, only a secondary to primary carbenium ion transition (mode $\mathrm{D}_{2}$ ) can occur. Transitions from a secondary carbenium ion to a secondary carbenium ion (mode $\mathrm{C}$ ) or to a tertiary carbenium ion (mode $\mathrm{B}_{1}$ ) are not explicitly considered as our MD simulations indicate that these cracking precursors tend to immediately isomerize to more stable tertiary carbenium ions. We therefore assume that 
isomerization occurs much faster than cracking and that the contribution of these $\beta$-scission modes will be minimal. For the $\mathrm{B}_{2}-1$ reaction, both static and molecular dynamics simulations are performed to evaluate the impact of true operating conditions on the cracking activity. For this particular reaction, this was possible since tertiary carbenium ions are still relatively stable at low temperature, ${ }^{27}$ and hence, they can be localized with static calculations.

3.2.1. Cracking Barriers from Static Calculations. First, static DFT calculations were performed at the PBE-D3 level of theory to quantify the intrinsic activation barrier for the cracking of a tertiary 2,4-dimethyl-2-hexyl carbenium ion (reaction $\mathrm{B}_{2}-1$ ). This tertiary, dibranched cation was found to be a very stable intermediate, and hence, it can be considered as a probable cracking reactant. Upon $\beta$-scission, isobutene and a 2 -butyl cation are formed. This reaction is an example of the $\mathrm{B}_{2}$ cracking mode in which a transition of a tertiary into a secondary carbenium ion takes place. To illustrate that a multitude of transition states exist and that the zeolite environment plays a crucial role in the stabilization of the transition state, four differently oriented transition state geometries around the BAS were localized, as shown in Figure 7. More information on the particular transition states and their geometrical characteristics is given in Section S10 of the SI.

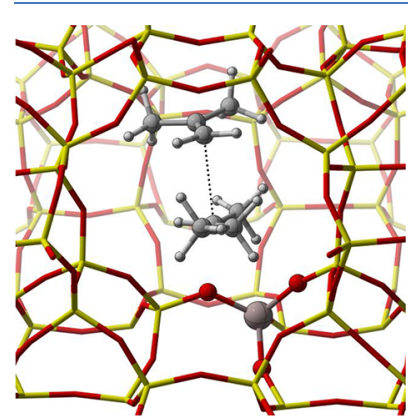

1

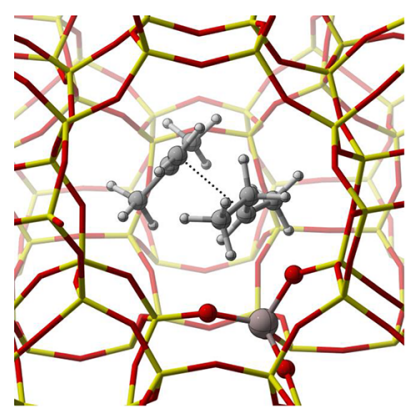

3

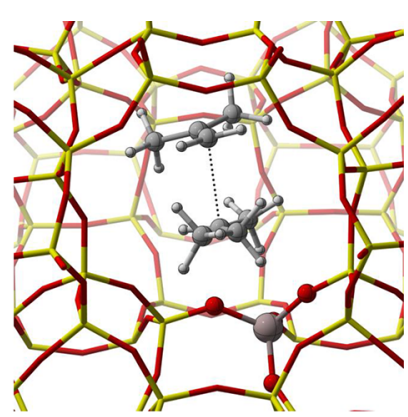

2

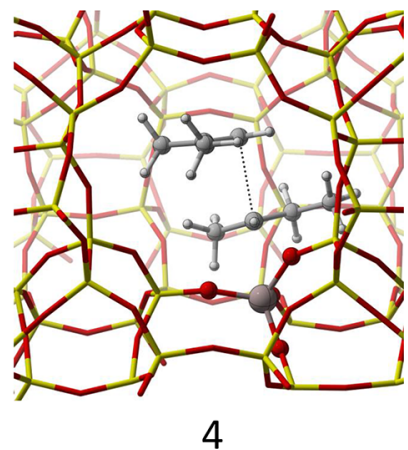

4
Figure 7. Sinusoidal channel view of the static geometries for the four $\mathrm{B}_{2}-1$ transition state structures.

In the optimized transition states, the 2-butyl cation interacts with both the isobutene $\mathrm{C}=\mathrm{C}$ bond and the nearest basic zeolite oxygen. In the product state, the 2-butyl cation immediately binds to the nearest framework oxygen, thus forming a 2-butoxide. Indeed, static calculations previously showed that 2-butoxide is substantially more stable than a 2butyl carbenium ion. ${ }^{27}$ However, at cracking temperatures, entropy contributions disfavor the formation of stable alkoxides, which is confirmed by the $\mathrm{MD}$ simulations on $\mathrm{C}_{4}$ species (Figure
$1)$, where the 2-butyl carbenium ion stabilizes by transforming into a $\pi$-complex.

The four different cracking reactions also show large energetic variations. Table 2 lists the enthalpy and free energy barriers at

Table 2. Enthaply, Entropy, and Free Energy Barriers at 773 $\mathrm{K}$ for the Four Conformations of 2,4-Dimethyl-2-hexyl Carbenium Ion Cracking (Reaction $\mathrm{B}_{2}-1$ )

$\begin{array}{cccc}\text { structure } & \Delta H_{\text {fwd }}^{\ddagger}(\mathrm{kJ} / \mathrm{mol}) & \Delta{S_{\text {fwd }}^{\ddagger}}^{\ddagger}(\mathrm{J} / \mathrm{mol} / \mathrm{K}) & \Delta G_{\text {fwd }}^{\ddagger}(\mathrm{kJ} / \mathrm{mol}) \\ 1 & 151 & -20 & 167 \\ 2 & 120 & -15 & 132 \\ 3 & 104 & -25 & 124 \\ 4 & 94 & 5 & 90\end{array}$

$773 \mathrm{~K}$. We notice large variations of almost $80 \mathrm{~kJ} / \mathrm{mol}$ on the forward activation barriers. This trend originates mainly from an enthalpy effect, but is enhanced by the entropy contributions. Upon studying the same $\mathrm{B}_{2}-1$ reaction, Mazar et al. also found a large variation $(82 \mathrm{~kJ} / \mathrm{mol})$ in activation energy between two distinct reaction configurations. ${ }^{74}$

These results show that many different pathways connect the reactant carbenium ion and cracked products, characterized by largely different activation barriers. The same feature has been reported for propane cracking in chabazite by Bucko et al. ${ }^{19}$ Alkene cracking reactions taking place at high temperature have a complex nature, where a restricted number of configurations on the PES are insufficient to capture the complexity of the transformation. In static calculations, only a single configuration of the adsorbed transition state is considered. Furthermore, the 0 $\mathrm{K}$ energy surface may differ from the free energy surface at cracking temperatures. ${ }^{21,28,98}$ The latter is evidenced by the 2butoxide formation in the product state. Additionally, the harmonic oscillator ( $\mathrm{HO}$ ) approximation underestimates the mobility of the adsorbates and entropy of the stationary states. ${ }^{129,130}$ Consequently, relying solely on static calculations seems insufficient to correctly describe the high-temperature cracking chemistry. Hereafter a more realistic study of the reactivity is performed based on molecular dynamics simulations at operating conditions.

3.2.2. Free-Energy Profiles for Cracking Reactions at Operating Conditions. To properly account for all possible reaction paths as well as finite temperature and entropy effects, the umbrella sampling technique is applied for determining cracking barriers. We first simulated both the $\beta$-scission of the 2,4-dimethyl-2-hexyl carbenium ion, reaction $\mathrm{B}_{2}-1$, and the 2,4dimethyl-4-hexyl carbenium ion, reaction $\mathrm{B}_{2}-2$ (Scheme 3). A broad range of transition states exists for these cracking reactions as indicated by the mobility plots shown in Figure $8 \mathrm{a}$. The red and blue dots represent the position of the center of mass of the two $\mathrm{C}_{4}$ fragments. During the umbrella sampling simulation, a large variety in the relative orientation of the two $\mathrm{C}_{4}$ fragments in the transition state region is sampled. The most visited configurations are localized in the straight channel or in the intersection of the straight and sinusoidal channel and resemble on average mostly the most stable static transition states ( 3 and 4). Figure $8 \mathrm{c}$ displays a superposition of transition state structures (corresponding to a collective variable value of 0.25 ) to show the conformational freedom in the activated complex region. Also the orientation of the breaking $\mathrm{C}-\mathrm{C}$ bond, indicated by the green bars, significantly fluctuates throughout the simulation. 


\section{(a)}

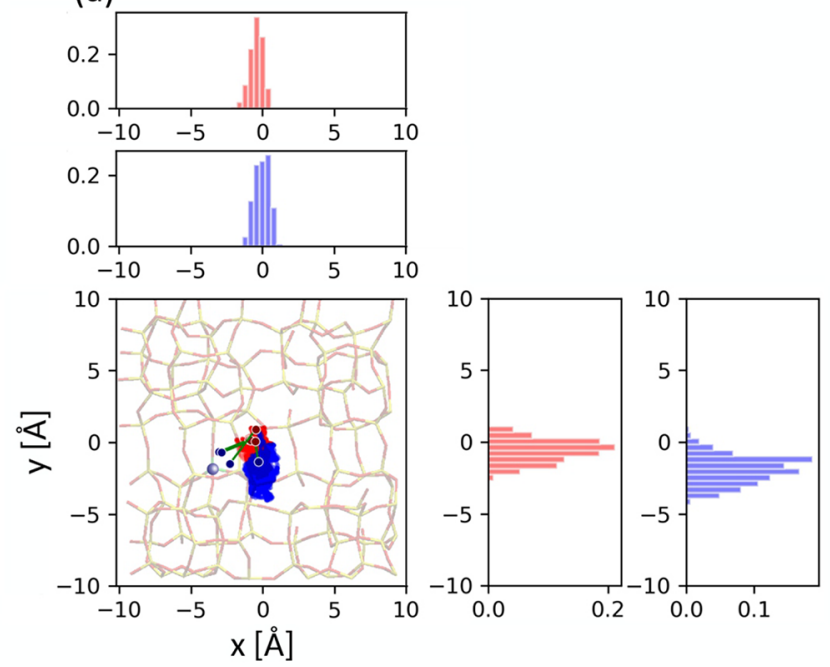

(b)

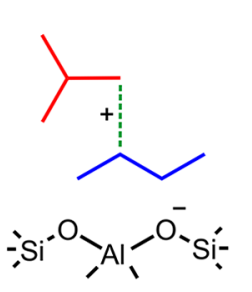

(c)

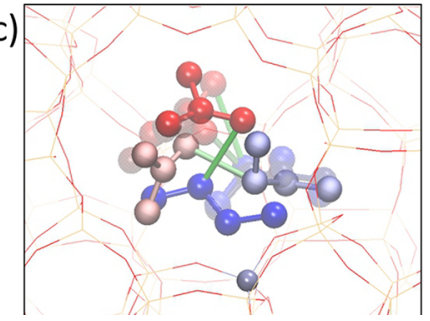

Figure 8. (a) Scatter plot of the center of mass of the transition state window configurations for the $\mathrm{B}_{2}-1$ cracking reaction in the channel system of H-ZSM-5, projected on the xy plane. The dots connected by green bars indicate the static transition state configurations. (b) Scheme of the $\mathrm{B}_{2}-1$ transition state with the isobutene fragment in red, the $n$ butyl fragment in blue and the breaking $\mathrm{C}-\mathrm{C}$ bond in green. (c) Superimposed snapshots of four different transition state window configurations. The purple sphere represents the location of the acid site.

The resulting free energy profiles are shown in Figure 9. For the two $\mathrm{B}_{2}$ type $\beta$-scissions, cracking barriers of 69 and $73 \mathrm{~kJ} /$ mol are obtained, respectively. These barriers are significantly lower than the lowest estimate predicted by static calculations $(90 \mathrm{~kJ} / \mathrm{mol})$. At $773 \mathrm{~K}$, the adsorbed species have a high mobility, allowing them to access many different configurations. On average, the sampled transition state configurations are mainly situated in the straight channel or at the intersection, but at longer distances from the framework compared to static calculations (see Figure S23). By considering just a single transition state and reactant configuration, static calculations clearly give an incomplete picture of the cracking barriers.

Furthermore, the height of the cracking barrier seems almost independent of the cracking products (isobutene/2-butyl cation or 2-methyl-1-butene/2-propyl cation). These findings indicate that the activation barrier is mainly determined by the type of $\beta$ scission mode-in this case a tertiary to secondary carbenium ion transition-rather than the type of alkene products formed in the reaction. The observation that reactions of the same cracking mode have similar free energy barriers is supported by von Aretin et al. ${ }^{131}$ They established a microkinetic model capable of correctly estimating alkene cracking product distributions with the assumption that cracking reactions of the same mode have the same rate coefficient.

Upon cracking, unstable secondary carbenium ion products are formed. As evidenced in earlier work, ${ }^{27,28}$ the $n$-propyl and $n$ -

butyl cations are unstable and will immediately rearrange. For these cracking products, two different transitions can be identified. The cation can either deprotonate to the framework or transfer a proton to the branched alkene product, thus forming two neutral alkenes or an alkene and tertiary carbenium ion as stable products. The latter rearrangement seems to be preferred as it was spontaneously observed in the US simulations. Static calculations on the two product states also confirmed that the alkene/tert-butyl cation products are about $12 \mathrm{~kJ} / \mathrm{mol}$ more stable than the alkene/alkene products. Once the cracking barrier is crossed, stabilizing isomerization reactions occur and the produced product fragments quickly diffuse away from each other, resulting in a sharp free energy drop (Figure 9a). Because of the large configurational space of the separate cracked fragments, the product state is insufficiently sampled to yield physically meaningful backward reaction barriers, hence these are not reported.

Second, we simulated the cracking of a 2-methyl-2-heptyl carbenium ion into isobutene and a 1-butyl carbenium ion (reaction $\mathrm{E}_{2}-1$ ). This cracking mode has a much higher activation barrier of $112 \mathrm{~kJ} / \mathrm{mol}$ (Figure 9c) which can be explained by the formation of an unstable primary cation in the transition state. After cracking, the unstable 1-butyl carbenium ion product instantly rearranges via a rapid hydride shift to a more stable secondary 2-butyl carbenium ion. The latter again undergoes a hydride shift with the formation of n-butene and a tert-butyl carbenium ion. This cracking mode is expected to be less important due to the primary carbenium ion character of the transition state. However, monobranched cracking precursors will exhibit less steric repulsion with the framework compared to highly branched alkenes and will therefore be more probable to occur.

Next, we simulated the cracking of the tribranched 2,4,4trimethyl-2-pentyl carbenium ion into isobutene and the tertbutyl carbenium ion (reaction A-1), the only possible A-mode cracking for $\mathrm{C}_{8}$ species. In Section 3.1.2, we showed that geminal substituted carbenium ions were more reactive than monobranched carbenium ions. Nevertheless, the 2,4,4-trimethyl-2pentyl cation was still observed as a stable intermediate. Since two stable products are formed upon cracking, also no product rearrangements are observed. As confirmed from the MD simulations, both states are long-living and coexist inside the zeolite pores. For this cracking mode, a relatively low barrier of $53 \mathrm{~kJ} / \mathrm{mol}$ (Figure 9d) is obtained which can be attributed to both the high reactivity of the cracking reactant and the formation of a stable tert-butyl cation in the transition state. However, the formation of highly branched cracking precursors may be prohibited due to steric constraints on ZSM-5. ${ }^{85,93,95}$ Indeed, the umbrella sampling simulations show a limited mobility for the 2,4,4-trimethyl-2-pentyl cation, which is mainly situated at the channel intersection.

Finally, we consider the cracking of a linear $\mathrm{C}_{8}$ carbenium ion $\left(\mathrm{D}_{2}\right.$ mode). Since secondary carbenium ions were shown to be relatively unstable cracking precursors with short lifetimes, the neutral alkene should rather be considered as cracking reactant. Therefore, two-dimensional umbrella sampling is performed with a first $\mathrm{CV}$ describing the protonation of 2 -octene and a second $\mathrm{CV}$ describing the $\beta$-scission of the resulting 3-octyl carbenium ion (reaction $\mathrm{D}_{2}-1$ ). The free energy profile for this cracking pathway is shown in Figure 10. For the protonation, an activation barrier of $55 \mathrm{~kJ} / \mathrm{mol}$ and a reaction free energy of 10 $\mathrm{kJ} / \mathrm{mol}$ are obtained, which is in good agreement with our MTD simulations (Table 1). For the cracking, a relatively high intrinsic 


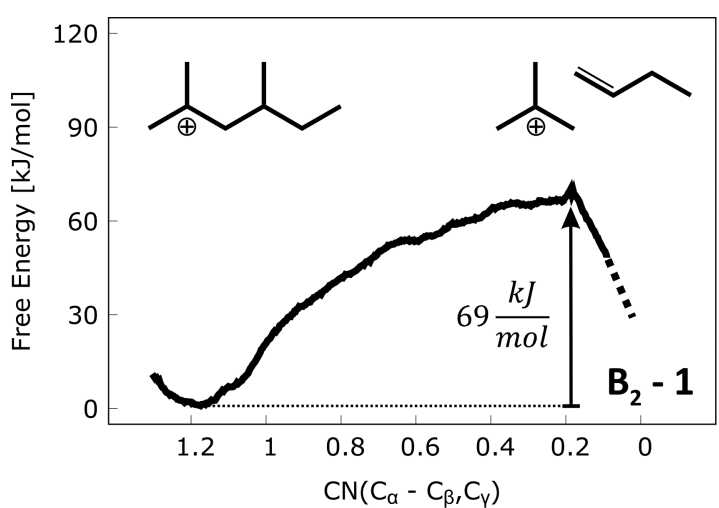

(a)

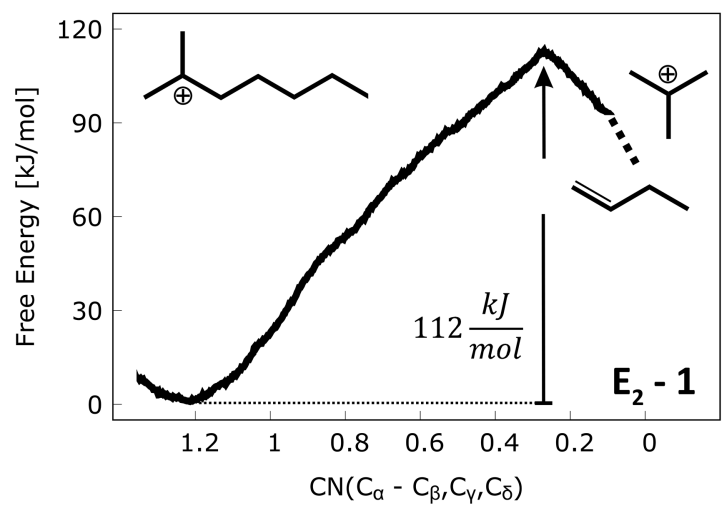

(c)

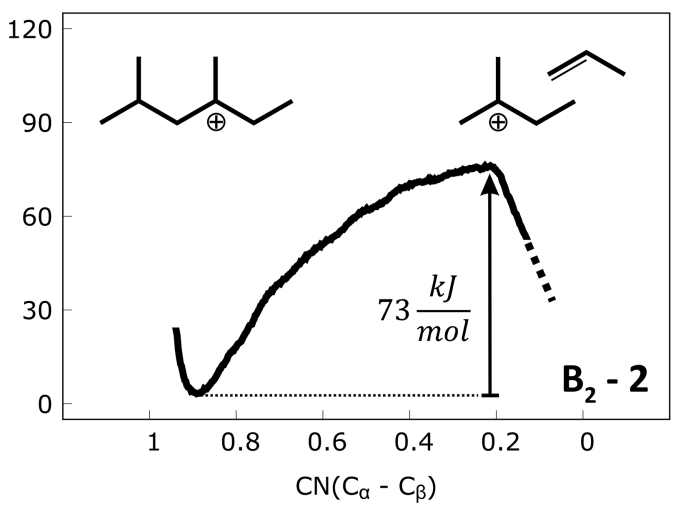

(b)

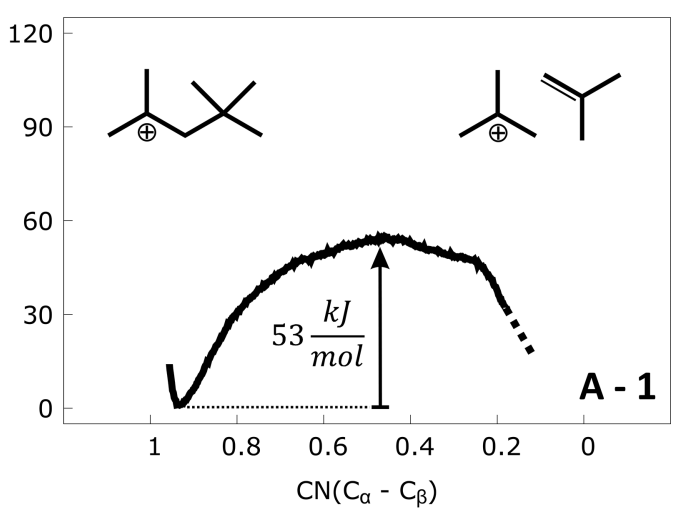

(d)

Figure 9. One-dimensional umbrella sampling free energy profiles at $773 \mathrm{~K}$ for the $\beta$-scission reactions $\mathrm{B}_{2}-1$ (a), $\mathrm{B}_{2}-2$ (b), $\mathrm{E}_{2}-1$ (c), $\mathrm{A}-1$ (d).

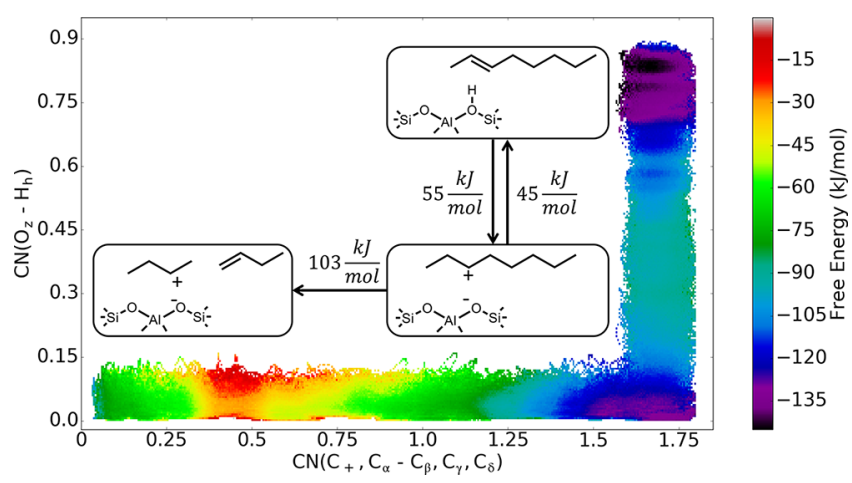

Figure 10. Two-dimensional umbrella sampling free energy profile at $773 \mathrm{~K}$ for the protonation of 2-octene and reaction $\mathrm{D}_{2}-1, \beta$-scission of the 3-octyl carbenium ion.

barrier of $103 \mathrm{~kJ} / \mathrm{mol}$ is obtained, which can again be explained by the combination of a relatively unstable reactant cation and an unstable product cation. The formation of a primary carbenium ion in the transition state is clearly unfavorable, yet unavoidable for linear chains. In the product state, the primary carbenium ion immediately isomerizes to a secondary carbenium ion. The latter is also expected to quickly stabilize by deprotonating to the framework, although this part of the reaction falls beyond the scope of the current study.

Our results allow an assessment of the importance of various alkene cracking modes from a theoretical perspective. Cracking mode A is by far the fastest, as it concerns a transition between tertiary carbenium ions. Such a cracking mode is only possible for alkenes with at least eight carbon atoms and three branches. Once formed, these precursors were found to have a reasonable lifetime at $773 \mathrm{~K}$ within ZSM-5, but their formation rate might be limited due to steric constraints. Type $\mathrm{B}_{2}$ cracking modes are expected to be very important cracking modes at operating conditions, given the fact that they start from stable carbenium ions and have relatively low intrinsic activation barriers. Cracking modes $\mathrm{B}_{1}$ which start from a secondary carbenium ion and yield a tertiary carbenium ion are expected to be less important because we found that the geminal methyl substituted cracking precursors (with a quaternary carbon atom) are extremely unstable. Cracking mode $\mathrm{C}$, a transition between secondary carbenium ions, is also predicted to be less important as the reactants will quickly rearrange into more stable tertiary carbenium ions. Cracking modes $\mathrm{D}_{2}$ and $\mathrm{E}_{2}$ both require the formation of a transition state with primary carbenium ion character, thus resulting in substantially higher intrinsic barriers. For cracking mode $\mathrm{D}_{2}$, the linear alkene reactant resides freely in the zeolite pores at the high temperature. In order to be reactive for $\beta$-scission, it first has to transform into a carbenium ion, which yields an additional contribution to the activation barrier for the $\mathrm{D}_{2}$ mode. The conclusions drawn here are in line with the experimental findings in the seminal papers of Weitkamp. ${ }^{95,99}$

\section{CONCLUSIONS}

Using advanced molecular dynamics simulations, catalytic alkene cracking pathways in H-ZSM-5 were studied at actual operating temperatures of $773 \mathrm{~K}$. Alkene cracking is known to proceed via a complex reaction network with many possible 
reaction routes and often elusive intermediates. At first instance the nature and stability of $\mathrm{C}_{4}-\mathrm{C}_{8}$ alkene cracking intermediates were determined. Over the course of the simulations, regular transitions were observed between a physisorbed van der Waals complex, a physisorbed $\pi$-complex, and a chemisorbed carbenium ion. Alkoxides, on the other hand, were not sampled and appear to be unstable at cracking conditions due to high entropic penalty for forming a covalent bond with the framework. Linear alkenes preferentially occur as a physisorbed $\pi$-complex or van der Waals complex. The latter is stabilized due to a higher mobility in the zeolite pore system. The stability of linear, secondary carbenium ions increases with carbon number, as the positive charge can be better delocalized over the carbon atoms along the chain. Linear alkenes first need to overcome the barrier for protonation before cracking reactions can occur. Free energies of activation for interconversion between a physisorbed alkene and a carbenium ion were determined using the metadynamics approach and amount to ca. $50 \mathrm{~kJ} / \mathrm{mol}$. For branched alkenes, carbenium ion intermediates were found to be more stable than physisorbed alkenes at cracking temperatures. No clear influence of the chain length could be observed. In contrast to linear carbenium ions, tertiary carbenium ions are undoubtedly very stable, long-living intermediates, which can act as cracking reactants. Secondary carbenium ions with geminal methyl branches though were shown to undergo rapid isomerization or $\beta$-scission into more stable carbenium ions.

In a next step, intrinsic barriers for $\beta$-scission reactions of mode $A, B_{2}, D_{2}$, and $E_{2}$ were determined using the umbrella sampling molecular dynamics technique. Overall, the importance of the various cracking modes was found to be determined by the interplay between the reactant carbocation stability and the transition state (or product) carbocation stability. Regardless of the formed products, similar cracking barriers are expected for reactions of the same $\beta$-scission mode (i.e., reactions with the same carbocation transition). Cracking modes $\mathrm{A}\left(3^{\circ} \rightarrow 3^{\circ}\right)$ and $\mathrm{B}_{2}\left(3^{\circ} \rightarrow 2^{\circ}\right)$ were found to be dominant at $773 \mathrm{~K}$, given the higher stability of branched cracking precursors and the lower free energy barriers for $\beta$ scission. Cracking modes $\mathrm{B}_{1}\left(2^{\circ} \rightarrow 3^{\circ}\right), \mathrm{C}\left(2^{\circ} \rightarrow 2^{\circ}\right), \mathrm{D}_{2}\left(2^{\circ} \rightarrow\right.$ $\left.1^{\circ}\right)$, and $\mathrm{E}_{2}\left(3^{\circ} \rightarrow 1^{\circ}\right)$ are expected to be less important. Mode $\mathrm{D}_{2}$ and $\mathrm{E}_{2}$ involve a transition state in which a unstable primary carbenium ion would be formed. Modes $\mathrm{B}_{1}, \mathrm{C}$, and $\mathrm{D}_{2}$ start from metastable, secondary carbenium ion reactants, which will typically undergo rapid isomerizations to more stable tertiary carbenium ions. While cracking mode A has a very low intrinsic barrier, the highly branched cracking precursors are very reactive and their formation may be sterically hindered in the zeolite pores.

The $\mathrm{B}_{2}$ cracking mode, starting from a very stable tertiary carbenium ion, was also studied with static DFT calculationsthe standard procedure to determine reactivity differences in current literature. Static cracking barriers were highly dependent on the particular orientation of the reactants and transition states in the zeolite channels. Furthermore, static calculations pointed to the formation of alkoxide products, which were proven to be nonexistent at high temperature. Standard DFT calculations are not capable of correctly predicting the stability of various cracking intermediates and do not account for the conformational freedom along the alkene cracking reaction profile. In contrast, consistent free energy barriers were obtained from umbrella sampling simulations which account for the full conformational mobility of all species at cracking temperatures. Our results clearly demonstrate the importance of simulations at operating conditions to assess the nature and reactivity of alkene cracking intermediates.

\section{ASSOCIATED CONTENT}

\section{Supporting Information}

The Supporting Information is available free of charge on the ACS Publications website at DOI: 10.1021/acscatal.8b01779.

Overview of static calculations, XYZ coordinates of static calculations, overview of MD simulations, computational details of MTD simulations, overview of MTD simulations, computational details of US simulations, XYZ coordinates of initial geometries of US simulations (PDF)

\section{AUTHOR INFORMATION}

\section{Corresponding Author}

*E-mail: Veronique.VanSpeybroeck@ugent.be.

ORCID

Ruben Demuynck: 0000-0003-3475-8808

Jeroen Van der Mynsbrugge: 0000-0003-3852-4726

Veronique Van Speybroeck: 0000-0003-2206-178X

\section{Present Address}

${ }^{\ddagger}$ Department of Chemical and Biomolecular Engineering, University of California, Berkeley, California 94720, United States

\section{Notes}

The authors declare no competing financial interest.

\section{ACKNOWLEDGMENTS}

The authors acknowledge the Fund for Scientific ResearchFlanders (FWO), the Research Board of Ghent University (BOF) and the European Union's Horizon 2020 research and innovation programme (consolidator ERC Grant Agreement No. 647755-DYNPOR (2015-2020)) for financial support. The computational resources and services used in this work were provided by VSC (Flemish Supercomputer Center), funded by the Hercules foundation and the Flemish Governmentdepartment EWI.

\section{REFERENCES}

(1) Guisnet, M.; Gilson, J.-P. Zeolites for Cleaner Technologies; Imperial College Press: London, 2002.

(2) Vermeiren, W.; Gilson, J.-P. Impact of Zeolites on the Petroleum and Petrochemical Industry. Top. Catal. 2009, 52, 1131-1161.

(3) Rahimi, N.; Karimzadeh, R. Catalytic Cracking of Hydrocarbons over Modified ZSM-5 Zeolites to Produce Light Olefins: A Review. Appl. Catal., A 2011, 398, 1-17.

(4) Hemelsoet, K.; Van der Mynsbrugge, J.; De Wispelaere, K.; Waroquier, M.; Van Speybroeck, V. Unraveling the Reaction Mechanisms Governing Methanol-to-Olefins Catalysis by Theory and Experiment. ChemPhysChem 2013, 14, 1526-1545.

(5) Tallman, M. J.; Eng, C. Consider New Catalytic Routes for Olefins Production - Innovative Catalyst Systems Enable Higher Propylene Make from Liquid Feedstocks. Hydrocarb. Process. 2008, 87, 95-101.

(6) Chen, J. Q.; Bozzano, A.; Glover, B.; Fuglerud, T.; Kvisle, S. Recent Advancements in Ethylene and Propylene Production Using the UOP/Hydro MTO Process. Catal. Today 2005, 106, 103-107.

(7) Plotkin, J. S. The Changing Dynamics of Olefin Supply/Demand. Catal. Today 2005, 106, 10-14.

(8) Bruijnincx, P. C. A.; Weckhuysen, B. M. Shale Gas Revolution: An Opportunity for the Production of Biobased Chemicals? Angew. Chem., Int. Ed. 2013, 52, 11980-11987.

(9) Amghizar, I.; Vandewalle, L. A.; Van Geem, K. M.; Marin, G. B. New Trends in Olefin Production. Engineering 2017, 3, 171-178. 
(10) Vogt, E. T. C.; Weckhuysen, B. M. Fluid Catalytic Cracking: Recent Developments on the Grand Old Lady of Zeolite Catalysis. Chem. Soc. Rev. 2015, 44, 7342-7370.

(11) Kissin, Y. V. Chemical Mechanisms of Catalytic Cracking Over Solid Acidic Catalysts: Alkanes and Alkenes. Catal. Rev.: Sci. Eng. 2001, $43,85-146$.

(12) Buchanan, J. S.; Santiesteban, J. G.; Haag, W. O. Mechanistic Considerations in Acid-Catalyzed Cracking of Olefins. J. Catal. 1996, 158, 279-287.

(13) Buurmans, I. L. C.; Weckhuysen, B. M. Heterogeneities of Individual Catalyst Particles in Space and Time as Monitored by Spectroscopy. Nat. Chem. 2012, 4, 873-886.

(14) Weckhuysen, B. M. Chemical Imaging of Spatial Heterogeneities in Catalytic Solids at Different Length and Time Scales. Angew. Chem., Int. Ed. 2009, 48, 4910-4943.

(15) Roeffaers, M. B. J.; De Cremer, G.; Libeert, J.; Ameloot, R.; Dedecker, P.; Bons, A.-J.; Bückins, M.; Martens, J. A.; Sels, B. F.; De Vos, D. E.; Hofkens, J. Super-Resolution Reactivity Mapping of Nanostructured Catalyst Particles. Angew. Chem. 2009, 121, 94499453.

(16) Van Speybroeck, V.; Hemelsoet, K.; Joos, L.; Waroquier, M.; Bell, R. G.; Catlow, C. R. A. Advances in Theory and Their Application within the Field of Zeolite Chemistry. Chem. Soc. Rev. 2015, 44, 70447111.

(17) Van Speybroeck, V.; De Wispelaere, K.; Van der Mynsbrugge, J.; Vandichel, M.; Hemelsoet, K.; Waroquier, M. First Principle Chemical Kinetics in Zeolites: The Methanol-to-Olefin Process as a Case Study. Chem. Soc. Rev. 2014, 43, 7326-7357.

(18) De Wispelaere, K.; Bailleul, S.; Van Speybroeck, V. Towards Molecular Control of Elementary Reactions in Zeolite Catalysis by Advanced Molecular Simulations Mimicking Operating Conditions. Catal. Sci. Technol. 2016, 6, 2686-2705.

(19) Bucko, T.; Benco, L.; Hafner, J.; Ángyán, J. G. Monomolecular Cracking of Propane over Acidic Chabazite: An Ab Initio Molecular Dynamics and Transition Path Sampling Study. J. Catal. 2011, 279, 220-228.

(20) Jiang, T.; Göltl, F.; Bulo, R. E.; Sautet, P. Effect of Temperature on the Adsorption of Short Alkanes in the Zeolite SSZ-13 - Adapting Adsorption Isotherms to Microporous Materials. ACS Catal. 2014, 4, 2351-2358.

(21) Zimmerman, P. M.; Tranca, D. C.; Gomes, J.; Lambrecht, D. S.; Head-Gordon, M.; Bell, A. T. Ab Initio Simulations Reveal That Reaction Dynamics Strongly Affect Product Selectivity for the Cracking of Alkanes over H-MFI. J. Am. Chem. Soc. 2012, 134, 19468-19476.

(22) Tranca, D. C.; Zimmerman, P. M.; Gomes, J.; Lambrecht, D.; Keil, F. J.; Head-Gordon, M.; Bell, A. T. Hexane Cracking on ZSM-5 and Faujasite Zeolites: A QM/MM/QCT Study. J. Phys. Chem. C 2015, $119,28836-28853$.

(23) Nieminen, V.; Sierka, M.; Murzin, D. Y.; Sauer, J. Stabilities of C3-C5 Alkoxide Species inside H-FER Zeolite: A Hybrid QM/MM Study. J. Catal. 2005, 231, 393-404.

(24) Boronat, M.; Viruela, P. M.; Corma, A. Reaction Intermediates in Acid Catalysis by Zeolites: Prediction of the Relative Tendency To Form Alkoxides or Carbocations as a Function of Hydrocarbon Nature and Active Site Structure. J. Am. Chem. Soc. 2004, 126, 3300-3309.

(25) Bhan, A.; Joshi, Y. V.; Delgass, W. N.; Thomson, K. T. DFT Investigation of Alkoxide Formation from Olefins in H-ZSM-5. J. Phys. Chem. B 2003, 107, 10476-10487.

(26) Ishikawa, H.; Yoda, E.; Kondo, J. N.; Wakabayashi, F.; Domen, K. Stable Dimerized Alkoxy Species of 2-Methylpropene on Mordenite Zeolite Studied by FT-IR. J. Phys. Chem. B 1999, 103, 5681-5686.

(27) Cnudde, P.; De Wispelaere, K.; Van der Mynsbrugge, J.; Waroquier, M.; Van Speybroeck, V. Effect of Temperature and Branching on the Nature and Stability of Alkene Cracking Intermediates in H-ZSM-5. J. Catal. 2017, 345, 53-69.

(28) Hajek, J.; Van der Mynsbrugge, J.; De Wispelaere, K.; Cnudde, P.; Vanduyfhuys, L.; Waroquier, M.; Van Speybroeck, V. On the Stability and Nature of Adsorbed Pentene in Brønsted Acid Zeolite HZSM-5 at 323 K. J. Catal. 2016, 340, 227-235.
(29) Haw, J. F.; Richardson, B. R.; Oshiro, I. S.; Lazo, N. D.; Speed, J. A. Reactions of Propene on Zeolite HY Catalyst Studied by in Situ Variable Temperature Solid-State Nuclear Magnetic Resonance Spectroscopy. J. Am. Chem. Soc. 1989, 111, 2052-2058.

(30) Lazo, N. D.; Richardson, B. R.; Schettler, P. D.; White, J. L.; Munson, E. J.; Haw, J. F. In Situ Variable-Temperature MAS Carbon-13 NMR Study of the Reactions of Isobutylene in Zeolites HY and HZSM5. J. Phys. Chem. 1991, 95, 9420-9425.

(31) Mal'kin, V. G.; Chesnokov, V. V.; Paukstis, E.; Zhidomirov, G. M. Quantum-Chemical Calculations of Carbon-13 Chemical Shifts of the Alkoxide Form in Zeolites. J. Am. Chem. Soc. 1990, 112, 666-669.

(32) Haw, J. F.; Nicholas, J. B.; Xu, T.; Beck, L. W.; Ferguson, D. B. Physical Organic Chemistry of Solid Acids: Lessons from in Situ NMR and Theoretical Chemistry. Acc. Chem. Res. 1996, 29, 259-267.

(33) Stepanov, A. G.; Zamaraev, K. I. ${ }^{13}$ C Solid State NMR Evidence for the Existence of Isobutyl Carbenium Ion in the Reaction of Isobutyl Alcohol Dehydration in H-ZSM-5 Zeolite. Catal. Lett. 1993, 19, 153158.

(34) Stepanov, A. G.; Luzgin, M. V.; Arzumanov, S. S.; Ernst, H.; Freude, D. N-Butene Conversion on H-Ferrierite Studied by ${ }^{13} \mathrm{C}$ MAS NMR. J. Catal. 2002, 211, 165-172.

(35) Stepanov, A. G.; Arzumanov, S. S.; Luzgin, M. V.; Ernst, H.; Freude, D. In Situ Monitoring of N-Butene Conversion on H-Ferrierite by ${ }^{1} \mathrm{H},{ }^{2} \mathrm{H}$, and ${ }^{13} \mathrm{C}$ MAS NMR: Kinetics of a Double-Bond-Shift Reaction, Hydrogen Exchange, and the ${ }^{13} \mathrm{C}$-Label Scrambling. J. Catal. 2005, 229, 243-251.

(36) Geobaldo, F.; Spoto, G.; Bordiga, S.; Lamberti, C.; Zecchina, A. Propene Oligomerization on H-Mordenite: Hydrogen-Bonding interaction, Chain Initiation, Propagation and Hydrogen Transfer studied by Temperature-Programmed FTIR and UV-VIS spectroscopies. J. Chem. Soc., Faraday Trans. 1997, 93, 1243-1249.

(37) Kondo, J. N.; Liqun, S.; Wakabayashi, F.; Domen, K. IR Study of Adsorption and Reaction of 1-Butene on H-ZSM-5. Catal. Lett. 1997, 47, 129-133.

(38) Kondo, J. N.; Wakabayashi, F.; Domen, K. IR Study of Reaction of 2-butene Adsorbed on Deuterated ZSM-5 and Mordenite. Catal. Lett. 1998, 53, 215-220.

(39) Kondo, J. N.; Domen, K.; Wakabayashi, F. Double Bond Migration of 1-Butene without Protonated Intermediate on D-ZSM-5. Microporous Mesoporous Mater. 1998, 21, 429-437.

(40) Kondo, J. N.; Wakabayashi, F.; Domen, K. IR Study of Adsorption of Olefins on Deuterated ZSM-5. J. Phys. Chem. B 1998, $102,2259-2262$

(41) Kondo, J. N.; Ishikawa, H.; Yoda, E.; Wakabayashi, F.; Domen, K. Structure of Dimerized Alkoxy Species of 2-Methylpropene on Zeolites and Silica-Alumina Studied by FT-IR. J. Phys. Chem. B 1999, 103, $8538-8543$.

(42) Rigby, A. M.; Kramer, G. J.; van Santen, R. A. Mechanisms of Hydrocarbon Conversion in Zeolites: A Quantum Mechanical Study. J. Catal. 1997, 170, 1-10.

(43) Boronat, M.; Viruela, P.; Corma, A. Theoretical Study of the Mechanism of Zeolite-Catalyzed Isomerization Reactions of Linear Butenes. J. Phys. Chem. A 1998, 102, 982-989.

(44) Kazanskii, V. B. The Nature of Adsorbed Carbenium Ions as Active Intermediates in Catalysis by Solid Acids. Acc. Chem. Res. 1991, 24, 379-383.

(45) Jeffrey Hay, P.; Redondo, A.; Guo, Y. Theoretical Studies of Pentene Cracking on Zeolites: $\mathrm{C}-\mathrm{C} \beta$-Scission Processes. Catal. Today $1999,50,517-523$.

(46) Rigby, A. M.; Frash, M. V. Ab Initio Calculations on the Mechanisms of Hydrocarbon Conversion in Zeolites: Skeletal Isomerisation and Olefin Chemisorption. J. Mol. Catal. A: Chem. 1997, 126, 61-72.

(47) Frash, M. V.; van Santen, R. A. Quantum-Chemical Modeling of the Hydrocarbon Transformations in Acid Zeolite Catalysts. Top. Catal. 1999, 9, 191-205.

(48) Frash, M. V.; Kazansky, V. B.; Rigby, A. M.; van Santen, R. A. Cracking of Hydrocarbons on Zeolite Catalysts: Density Functional 
and Hartree-Fock Calculations on the Mechanism of the $\beta$-Scission Reaction. J. Phys. Chem. B 1998, 102, 2232-2238.

(49) Blaszkowski, S. R.; Nascimento, M. A. C.; van Santen, R. A. Activation of $\mathrm{C}-\mathrm{H}$ and $\mathrm{C}-\mathrm{C}$ Bonds by an Acidic Zeolite: A Density Functional Study. J. Phys. Chem. 1996, 100, 3463-3472.

(50) Sarazen, M. L.; Doskocil, E.; Iglesia, E. Catalysis on Solid Acids: Mechanism and Catalyst Descriptors in Oligomerization Reactions of Light Alkenes. J. Catal. 2016, 344, 553-569.

(51) Sarazen, M. L.; Iglesia, E. Stability of Bound Species during Alkene Reactions on Solid Acids. Proc. Natl. Acad. Sci. U. S. A. 2017, 114, E3900-E3908.

(52) Svelle, S.; Kolboe, S.; Swang, O. Theoretical Investigation of the Dimerization of Linear Alkenes Catalyzed by Acidic Zeolites. J. Phys. Chem. B 2004, 108, 2953-2962.

(53) Wang, W.; Hunger, M. Reactivity of Surface Alkoxy Species on Acidic Zeolite Catalysts. Acc. Chem. Res. 2008, 41, 895-904.

(54) Natal-Santiago, M. A.; Alcalá, R.; Dumesic, J. A. DFT Study of the Isomerization of Hexyl Species Involved in the Acid-Catalyzed Conversion of 2-Methyl-Pentene-2. J. Catal. 1999, 181, 124-144.

(55) Boronat, M.; Zicovich-Wilson, C. M.; Viruela, P.; Corma, A. Influence of the Local Geometry of Zeolite Active Sites and Olefin Size on the Stability of Alkoxide Intermediates. J. Phys. Chem. B 2001, 105, 11169-11177.

(56) Corma, A.; Orchillés, A. V. Current Views on the Mechanism of Catalytic Cracking. Microporous Mesoporous Mater. 2000, 35-36, 2130.

(57) Swisher, J. A.; Hansen, N.; Maesen, T.; Keil, F. J.; Smit, B.; Bell, A. T. Theoretical Simulation of N-Alkane Cracking on Zeolites. J. Phys. Chem. C 2010, 114, 10229-10239.

(58) Guo, Y.-H.; Pu, M.; Chen, B.-H.; Cao, F. Theoretical Study on the Cracking Reaction Catalyzed by a Solid Acid with Zeolitic Structure: The Catalytic Cracking of 1-Hexene on the Surface of $\mathrm{H}$ ZSM-5. Appl. Catal., A 2013, 455, 65-70.

(59) East, A. L. L.; Bučko, T.; Hafner, J. On the Structure and Dynamics of Secondary N-Alkyl Cations. J. Chem. Phys. 2009, 131, 104314.

(60) Fang, H.; Zheng, A.; Li, S.; Xu, J.; Chen, L.; Deng, F. New Insights into the Effects of Acid Strength on the Solid Acid-Catalyzed Reaction: Theoretical Calculation Study of Olefinic Hydrocarbon Protonation Reaction. J. Phys. Chem. C 2010, 114, 10254-10264.

(61) Fang, H.; Zheng, A.; Xu, J.; Li, S.; Chu, Y.; Chen, L.; Deng, F. Theoretical Investigation of the Effects of the Zeolite Framework on the Stability of Carbenium Ions. J. Phys. Chem. C 2011, 115, 7429-7439.

(62) Benco, L.; Hafner, J.; Hutschka, F.; Toulhoat, H. Physisorption and Chemisorption of Some N-Hydrocarbons at the Brønsted Acid Site in Zeolites 12-Membered Ring Main Channels: Ab Initio Study of the Gmelinite Structure. J. Phys. Chem. B 2003, 107, 9756-9762.

(63) Benco, L.; Demuth, T.; Hafner, J.; Hutschka, F.; Toulhoat, H. Linear Hydrocarbons Adsorbed in the Acid Zeolite Gmelinite at $700 \mathrm{~K}$ $\mathrm{Ab}$ Initio Molecular Dynamics Simulation of Hexane and Hexene. J. Catal. 2002, 205, 147-156.

(64) Chu, Y.; Han, B.; Zheng, A.; Deng, F. Influence of Acid Strength and Confinement Effect on the Ethylene Dimerization Reaction over Solid Acid Catalysts: A Theoretical Calculation Study. J. Phys. Chem. C 2012, 116, 12687-12695.

(65) Lin, L.; Qiu, C.; Zhuo, Z.; Zhang, D.; Zhao, S.; Wu, H.; Liu, Y.; $\mathrm{He}, \mathrm{M}$. Acid Strength Controlled Reaction Pathways for the Catalytic Cracking of 1-Butene to Propene over ZSM-5. J. Catal. 2014, 309, 136145.

(66) Lin, L. F.; Zhao, S. F.; Zhang, D. W.; Fan, H.; Liu, Y. M.; He, M. Y. Acid Strength Controlled Reaction Pathways for the Catalytic Cracking of 1-Pentene to Propene over ZSM-5. ACS Catal. 2015, 5, 4048-4059.

(67) Wang, C.-M.; Brogaard, R. Y.; Weckhuysen, B. M.; Nørskov, J. K.; Studt, F. Reactivity Descriptor in Solid Acid Catalysis: Predicting Turnover Frequencies for Propene Methylation in Zeotypes. J. Phys. Chem. Lett. 2014, 5, 1516-1521.

(68) Tuma, C.; Sauer, J. Protonated Isobutene in Zeolites: Tert-Butyl Cation or Alkoxide? Angew. Chem. 2005, 117, 4847-4849.
(69) Tuma, C.; Kerber, T.; Sauer, J. The Tert-Butyl Cation in HZeolites: Deprotonation to Isobutene and Conversion into Surface Alkoxides. Angew. Chem., Int. Ed. 2010, 49, 4678-4680.

(70) Nguyen, C. M.; De Moor, B. A.; Reyniers, M.-F.; Marin, G. B. Isobutene Protonation in H-FAU, H-MOR, H-ZSM-5, and H-ZSM-22. J. Phys. Chem. C 2012, 116, 18236-18249.

(71) Rosenbach, N., Jr.; dos Santos, A. P. A.; Franco, M.; Mota, C. J. A. The Tert-Butyl Cation on Zeolite Y: A Theoretical and Experimental Study. Chem. Phys. Lett. 2010, 485, 124-128.

(72) Dai, W.; Wang, C.; Yi, X.; Zheng, A.; Li, L.; Wu, G.; Guan, N.; Xie, Z.; Dyballa, M.; Hunger, M. Identification of Tert-Butyl Cations in Zeolite H-ZSM-5: Evidence from NMR Spectroscopy and DFT Calculations. Angew. Chem., Int. Ed. 2015, 54, 8783-8786.

(73) Sun, Y.-X.; Yang, J.; Zhao, L.-F.; Dai, J.-X.; Sun, H. A Two-Layer ONIOM Study on Initial Reactions of Catalytic Cracking of 1-Butene to Produce Propene and Ethene over HZSM-5 and HFAU Zeolites. J. Phys. Chem. C 2010, 114, 5975-5984.

(74) Mazar, M. N.; Al-Hashimi, S.; Cococcioni, M.; Bhan, A. $\beta$ Scission of Olefins on Acidic Zeolites: A Periodic PBE-D Study in $\mathrm{H}-$ ZSM-5. J. Phys. Chem. C 2013, 117, 23609-23620.

(75) Chen, C.-J.; Rangarajan, S.; Hill, I. M.; Bhan, A. Kinetics and Thermochemistry of $\mathrm{C}_{4}-\mathrm{C}_{6}$ Olefin Cracking on H-ZSM-5. ACS Catal. 2014, 4, 2319-2327.

(76) Abbot, J.; Wojciechowski, B. The Mechanism of Catalytic Cracking of Normal-Alkenes on ZSM-5 Zeolite. Can. J. Chem. Eng. 1985, 63, 462-469.

(77) Buchanan, J. S. Reactions of Model Compounds over Steamed ZSM-5 at Simulated FCC Reaction Conditions. Appl. Catal. 1991, 74, $83-94$.

(78) Bortnovsky, O.; Sazama, P.; Wichterlova, B. Cracking of Pentenes to $\mathrm{C}_{2}-\mathrm{C}_{4}$ Light Olefins over Zeolites and Zeotypes: Role of Topology and Acid Site Strength and Concentration. Appl. Catal., A 2005, 287, 203-213.

(79) Borges, P.; Pinto, R. R.; Lemos, M. A. N. D. A.; Lemos, F.; Védrine, J. C.; Derouane, E. G.; Ribeiro, F. R. Light Olefin Transformation over ZSM-5 Zeolites: A Kinetic Model for Olefin Consumption. Appl. Catal., A 2007, 324, 20-29.

(80) Oliveira, P.; Borges, P.; Pinto, R. R.; Lemos, M. A. N. D. A.; Lemos, F.; Védrine, J. C.; Ribeiro, F. R. Light Olefin Transformation over ZSM-5 Zeolites with Different Acid Strengths - A Kinetic Model. Appl. Catal., A 2010, 384, 177-185.

(81) Meng, X.; Xu, C.; Li, L.; Gao, J. Kinetic Study of Catalytic Pyrolysis of $\mathrm{C}_{4}$ Hydrocarbons on a Modified ZSM-5 Zeolite Catalyst. Energy Fuels 2010, 24, 6233-6238.

(82) Zhu, X.; Liu, S.; Song, Y.; Xie, S.; Xu, L. Catalytic Cracking of 1Butene to Propene and Ethene on MCM-22 Zeolite. Appl. Catal., A 2005, 290, 191-199.

(83) Miyaji, A.; Sakamoto, Y.; Iwase, Y.; Yashima, T.; Koide, R.; Motokura, K.; Baba, T. Selective Production of Ethylene and Propylene via Monomolecular Cracking of Pentene over Proton-Exchanged Zeolites: Pentene Cracking Mechanism Determined by Spatial Volume of Zeolite Cavity. J. Catal. 2013, 302, 101-114.

(84) Huang, X.; Aihemaitijiang, D.; Xiao, W.-D. Reaction Pathway and Kinetics of $\mathrm{C}_{3}-\mathrm{C}_{7}$ Olefin Transformation over High-Silicon HZSM-5 Zeolite at $400-490^{\circ}$ C. Chem. Eng. J. 2015, 280, 222-232.

(85) von Aretin, T.; Hinrichsen, O. Single-Event Kinetic Model for Cracking and Isomerization of 1-Hexene on ZSM-5. Ind. Eng. Chem. Res. 2014, 53, 19460-19470.

(86) von Aretin, T.; Schallmoser, S.; Standl, S.; Tonigold, M.; Lercher, J. A.; Hinrichsen, O. Single-Event Kinetic Model for 1-Pentene Cracking on ZSM-5. Ind. Eng. Chem. Res. 2015, 54, 11792-11803.

(87) Ying, L.; Zhu, J.; Cheng, Y.; Wang, L.; Li, X. Kinetic Modeling of $\mathrm{C}_{2}-\mathrm{C}_{7}$ Olefins Interconversion over ZSM-5 Catalyst. J. Ind. Eng. Chem. 2016, 33, 80-90.

(88) Epelde, E.; Aguayo, A. T.; Olazar, M.; Bilbao, J.; Gayubo, A. G. Kinetic Model for the Transformation of 1-Butene on a K-Modified HZSM-5 Catalyst. Ind. Eng. Chem. Res. 2014, 53, 10599-10607. 
(89) Standl, S.; Tonigold, M.; Hinrichsen, O. Single-Event Kinetic Modeling of Olefin Cracking on ZSM-5: Proof of Feed Independence. Ind. Eng. Chem. Res. 2017, 56, 13096-13108.

(90) Quann, R. J.; Green, L. A.; Tabak, S. A.; Krambeck, F. J. Chemistry of Olefin Oligomerization over ZSM-5 Catalyst. Ind. Eng. Chem. Res. 1988, 27, 565-570.

(91) Koyama, T.; Hayashi, Y.; Horie, H.; Kawauchi, S.; Matsumoto, A.; Iwase, Y.; Sakamoto, Y.; Miyaji, A.; Motokura, K.; Baba, T. Key Role of the Pore Volume of Zeolite for Selective Production of Propylene from Olefins. Phys. Chem. Chem. Phys. 2010, 12, 2541-2554.

(92) Iwase, Y.; Sakamoto, Y.; Shiga, A.; Miyaji, A.; Motokura, K.; Koyama, T.; Baba, T. Shape-Selective Catalysis Determined by the Volume of a Zeolite Cavity and the Reaction Mechanism for Propylene Production by the Conversion of Butene Using a Proton-Exchanged Zeolite. J. Phys. Chem. C 2012, 116, 5182-5196.

(93) Abbot, J.; Wojciechowski, B. W. Catalytic Cracking and Skeletal Isomerization of N-Hexene on ZSM-5 Zeolite. Can. J. Chem. Eng. 1985, 63, 451-461.

(94) Tabak, S. A.; Krambeck, F. J.; Garwood, W. E. Conversion of Propylene and Butylene over ZSM-5 Catalyst. AIChE J. 1986, 32, $1526-1531$.

(95) Weitkamp, J. Catalytic Hydrocracking - Mechanisms and Versatility of the Process. Chem CatChem 2012, 4, 292-306.

(96) Lesthaeghe, D.; Van der Mynsbrugge, J.; Vandichel, M.; Waroquier, M.; Van Speybroeck, V. Full Theoretical Cycle for Both Ethene and Propene Formation during Methanol-to-Olefin Conversion in H-ZSM-5. ChemCatChem 2011, 3, 208-212.

(97) Bučko, T.; Benco, L.; Dubay, O.; Dellago, C.; Hafner, J. Mechanism of Alkane Dehydrogenation Catalyzed by Acidic Zeolites: Ab Initio Transition Path Sampling. J. Chem. Phys. 2009, 131, 214508.

(98) Göltl, F.; Hafner, J. Modelling the Adsorption of Short Alkanes in Protonated Chabazite: The Impact of Dispersion Forces and Temperature. Microporous Mesoporous Mater. 2013, 166, 176-184.

(99) Weitkamp, J.; Jacobs, P. A.; Martens, J. A. Isomerization and Hydrocracking of $\mathrm{C}_{9}$ through $\mathrm{C}_{16} \mathrm{~N}$-Alkanes on Pt/HZSM-5 Zeolite. Appl. Catal. 1983, 8, 123-141.

(100) Kresse, G.; Hafner, J. Ab Initio Molecular Dynamics for Liquid Metals. Phys. Rev. B: Condens. Matter Mater. Phys. 1993, 47, 558-561.

(101) Kresse, G.; Hafner, J. Ab Initio Molecular-Dynamics Simulation of the Liquid-Metal Amorphous-Semiconductor Transition in Germanium. Phys. Rev. B: Condens. Matter Mater. Phys. 1994, 49, 14251-14269.

(102) Kresse, G.; Furthmüller, J. Efficiency of Ab-Initio Total Energy Calculations for Metals and Semiconductors Using a Plane-Wave Basis Set. Comput. Mater. Sci. 1996, 6, 15-50.

(103) Kresse, G.; Furthmüller, J. Efficient Iterative Schemes for Ab Initio Total-Energy Calculations Using a Plane-Wave Basis Set. Phys. Rev. B: Condens. Matter Mater. Phys. 1996, 54, 11169-11186.

(104) Heyden, A.; Bell, A. T.; Keil, F. J. Efficient Methods for Finding Transition States in Chemical Reactions: Comparison of Improved Dimer Method and Partitioned Rational Function Optimization Method. J. Chem. Phys. 2005, 123, 224101.

(105) Perdew, J. P.; Burke, K.; Ernzerhof, M. Generalized Gradient Approximation Made Simple. Phys. Rev. Lett. 1996, 77, 3865-3868.

(106) Grimme, S.; Antony, J.; Ehrlich, S.; Krieg, H. A Consistent and Accurate Ab Initio Parametrization of Density Functional Dispersion Correction (DFT-D) for the 94 Elements H-Pu. J. Chem. Phys. 2010, $132,154104$.

(107) Kresse, G.; Joubert, D. From Ultrasoft Pseudopotentials to the Projector Augmented-Wave Method. Phys. Rev. B: Condens. Matter Mater. Phys. 1999, 59, 1758-1775.

(108) Blöchl, P. E. Projector Augmented-Wave Method. Phys. Rev. B: Condens. Matter Mater. Phys. 1994, 50, 17953-17979.

(109) Ghysels, A.; Van Neck, D.; Waroquier, M. Cartesian Formulation of the Mobile Block Hessian Approach to Vibrational Analysis in Partially Optimized Systems. J. Chem. Phys. 2007, 127, 164108.

(110) Reetz, M. T.; Meiswinkel, A.; Mehler, G.; Angermund, K.; Graf, M.; Thiel, W.; Mynott, R.; Blackmond, D. G. Why Are BINOL-Based
Monophosphites Such Efficient Ligands in Rh-Catalyzed Asymmetric Olefin Hydrogenation? J. Am. Chem. Soc. 2005, 127, 10305-10313.

(111) Donoghue, P. J.; Helquist, P.; Norrby, P.-O.; Wiest, O. Development of a Q2MM Force Field for the Asymmetric Rhodium Catalyzed Hydrogenation of Enamides. J. Chem. Theory Comput. 2008, 4, 1313-1323.

(112) Ghysels, A.; Verstraelen, T.; Hemelsoet, K.; Waroquier, M.; Van Speybroeck, V. TAMkin: A Versatile Package for Vibrational Analysis and Chemical Kinetics. J. Chem. Inf. Model. 2010, 50, 1736-1750.

(113) VandeVondele, J.; Krack, M.; Mohamed, F.; Parrinello, M.; Chassaing, T.; Hutter, J. QUICKSTEP: Fast and Accurate Density Functional Calculations Using a Mixed Gaussian and Plane Waves Approach. Comput. Phys. Commun. 2005, 167, 103-128.

(114) Yang, K.; Zheng, J.; Zhao, Y.; Truhlar, D. G. Tests of the RPBE, RevPBE, $\tau$-HCTHhyb, $\Omega$ B97X-D, and MOHLYP Density Functional Approximations and 29 Others against Representative Databases for Diverse Bond Energies and Barrier Heights in Catalysis. J. Chem. Phys. 2010, 132, 164117.

(115) Goedecker, S.; Teter, M.; Hutter, J. Separable Dual-Space Gaussian Pseudopotentials. Phys. Rev. B: Condens. Matter Mater. Phys. 1996, 54, 1703-1710.

(116) Lippert, G.; Hutter, J.; Parrinello, M. The Gaussian and Augmented-Plane-Wave Density Functional Method for Ab Initio Molecular Dynamics Simulations. Theor. Chem. Acc. 1999, 103, 124140.

(117) Lippert, G.; Hutter, J.; Parrinello, M. A Hybrid Gaussian and Plane Wave Density Functional Scheme. Mol. Phys. 1997, 92, 477-488.

(118) Nosé, S. A Molecular Dynamics Method for Simulations in the Canonical Ensemble. Mol. Phys. 1984, 52, 255-268.

(119) Martyna, G. J.; Klein, M. L.; Tuckerman, M. Nosé-Hoover Chains: The Canonical Ensemble via Continuous Dynamics. J. Chem. Phys. 1992, 97, 2635-2643.

(120) Laio, A.; Parrinello, M. Escaping Free-Energy Minima. Proc. Natl. Acad. Sci. U. S. A. 2002, 99, 12562-12566.

(121) Laio, A.; Gervasio, F. L. Metadynamics: A Method to Simulate Rare Events and Reconstruct the Free Energy in Biophysics, Chemistry and Material Science. Rep. Prog. Phys. 2008, 71, 126601.

(122) Bussi, G.; Laio, A.; Parrinello, M. Equilibrium Free Energies from Nonequilibrium Metadynamics. Phys. Rev. Lett. 2006, 96, 090601.

(123) Torrie, G. M.; Valleau, J. P. Monte Carlo Free Energy Estimates Using Non-Boltzmann Sampling: Application to the Sub-Critical Lennard-Jones Fluid. Chem. Phys. Lett. 1974, 28, 578-581.

(124) Torrie, G. M.; Valleau, J. P. Nonphysical Sampling Distributions in Monte Carlo Free-Energy Estimation: Umbrella Sampling. J. Comput. Phys. 1977, 23, 187-199.

(125) Tribello, G. A.; Bonomi, M.; Branduardi, D.; Camilloni, C.; Bussi, G. PLUMED 2: New Feathers for an Old Bird. Comput. Phys. Commun. 2014, 185, 604-613.

(126) Kumar, S.; Rosenberg, J. M.; Bouzida, D.; Swendsen, R. H.; Kollman, P. A. THE Weighted Histogram Analysis Method for FreeEnergy Calculations on Biomolecules. I. The Method. J. Comput. Chem. 1992, 13, 1011-1021.

(127) Souaille, M.; Roux, B. Extension to the Weighted Histogram Analysis Method: Combining Umbrella Sampling with Free Energy Calculations. Comput. Phys. Commun. 2001, 135, 40-57.

(128) Grossfield, A. WHAM: The Weighted Histogram Analysis Method, Version 2.0.9. See the following: http://Membrane.Urmc. Rochester.Edu/Content/Wham.

(129) De Moor, B. A.; Ghysels, A.; Reyniers, M.-F.; Van Speybroeck, V.; Waroquier, M.; Marin, G. B. Normal Mode Analysis in Zeolites: Toward an Efficient Calculation of Adsorption Entropies. J. Chem. Theory Comput. 2011, 7, 1090-1101.

(130) Van der Mynsbrugge, J.; Janda, A.; Mallikarjun Sharada, S.; Lin, L.-C.; Van Speybroeck, V.; Head-Gordon, M.; Bell, A. T. Theoretical Analysis of the Influence of Pore Geometry on Monomolecular Cracking and Dehydrogenation of N-Butane in Brønsted Acidic Zeolites. ACS Catal. 2017, 7, 2685-2697.

(131) von Aretin, T.; Standl, S.; Tonigold, M.; Hinrichsen, O. Optimization of the Product Spectrum for 1-Pentene Cracking on 
ZSM-5 Using Single-Event Methodology. Part 2: Recycle Reactor. Chem. Eng. J. 2017, 309, 873-885. 